\title{
El acceso de los representantes políticos a la información y la nueva normativa sobre transparencia y acceso a la información pública. En especial, la posibilidad de presentar reclamaciones ante las Autoridades de transparencia
}

\author{
The access of political representatives to information and the \\ new laws on transparency and access to public information. \\ In particular, their capacity to file claims with the transparency \\ authorities
}

Emilio Guichot

Universidad de Sevilla eguichot@us.es

\begin{abstract}
RESUMEN
Las nuevas Autoridades independientes de transparencia han adoptado posiciones enfrentadas sobre cuál sea la normativa aplicable a las solicitudes de información realizadas por los representantes políticos y acerca de su propia competencia para conocer las reclamaciones que éstos puedan plantear. El derecho de acceso a la información de los representantes políticos no puede tener un alcance menor en su contenido sustantivo, procedimental y de garantías que el que la nueva normativa sobre transparencia y acceso a la información reconoce a cualquier persona. La jurisprudencia del Tribunal Supremo lo ha afirmado de forma rotunda. Contribuiría a la seguridad jurídica que este criterio se asentara en la doctrina de las Autoridades independientes de transparencia y que una reforma legislativa lo contemplara expresamente.
\end{abstract}

\section{PALABRAS CLAVE}

Acceso a la información, transparencia, rendición de cuentas, representantes políticos, concejales, parlamentarios, artículo 23.2 Constitución española, artículo $77 \mathrm{lbrl}$, autoridades de transparencia.

\begin{abstract}
The new public independent authorities in charge of access to information's claims have adopted conflicting positions on the rules applicable to requests for information made by political representatives and on their own competence to hear complaints they may raise. The right of access to the information of the political representatives cannot have a smaller scope in its substantive, procedural and guarantees content than the one that the new regulation on transparency and access to the information recognizes to any person. The case law of the Supreme Court has consistently affirmed this. It would contribute to legal certainty if this criterion was followed by every new public independent authorities and it was expressly established by a future legislative reform.
\end{abstract}

\section{KEYWORDS}

Access to information, freedom of information, transparency, accountability, political representatives, article 23.2 Spanish constitution, article 77 local government act, transparency authorities. 


\begin{abstract}
SUMARIO
I. APROXIMACIÓN GENERAL: UNA CIERTA PERPLEJIDAD. II. LAS DIFERENTES POSICIONES DE LAS AUTORIDADES INDEPENDIENTES DE TRANSPARENCIA. 1. La plena libertad de los representantes políticos para determinar el bloque normativo aplicable, con admisión de las reclamaciones solo en los casos en que se ha invocado expresamente la normativa sobre transparencia, y sin posibilidad de recurrir al «espigueo» para pretender la aplicación de las previsiones más favorables de uno y otro bloque normativo. 2. Una vuelta de tuerca: la limitación de la posibilidad del representante político para acogerse a la normativa general y la consiguiente inadmisión de las reclamaciones cuando antes se solicitó la misma información en calidad de representante político. 3. La competencia de las Autoridades de transparencia para conocer las reclamaciones presentadas por representantes políticos, también cuando se invoca la normativa especial, por la aplicación supletoria de la normativa general sobre transparencia y acceso a la información y la procedencia del "espigueo» a la hora de aplicar las normas sustantivas o procedimentales de la normativa general si son más favorables al derecho de acceso. III. VALORACIÓN Y CONCLUSIONES. 1. La competencia de las Autoridades de transparencia para conocer de las reclamaciones interpuestas por representantes políticos en su condición de tales. 2. La aplicación a los representantes políticos de su normativa específica sólo en lo que sea más favorable al derecho de acceso que la normativa general. Acerca del del «espigueo».
\end{abstract}

\title{
I. APROXIMACIÓN GENERAL: UNA CIERTA PERPLEJIDAD
}

En este trabajo voy a abordar un tema concreto y actualmente polémico, cual es el de si los representantes políticos, cuando solicitan acceso a la información para el ejercicio de sus funciones, pueden acudir a la vía de reclamación ante las Autoridades independientes de transparencia previstas en la normativa general sobre transparencia y acceso a la información, estatal y autonómica, que se ha ido aprobando en estos últimos años. Haré también una reflexión inicial y final más amplia sobre la incidencia de esta nueva normativa en la interpretación de la normativa especial que regula el acceso de los representantes políticos a la información.

Hemos de partir de que la Ley 19/2013, de 9 de diciembre, de transparencia y acceso a la información y buen gobierno (LTBG), que establece la regulación básica estatal sobre la materia, dispone en el segundo apartado de su disposición adicional primera, titulada «regulaciones especiales del derecho de acceso a la información», que «se regirán por su normativa específica, y por esta Ley con carácter supletorio, aquellas materias que tengan previsto un régimen jurídico específico de acceso a la información» ${ }^{1}$. La LTBG no desvela cuáles sean estas normativas específicas, a diferencia de lo que hacía el propio art. 37 de la Ley 30/1992, en su apartado sexto, en el que se enumeraban las materias que se regían por su normativa específica, entre las que se encontraba la que ahora estudiamos, sin referencia alguna a la supletoriedad.

En trabajos anteriores, ya reflexioné sobre cuál había de ser la influencia que la aprobación de esta normativa habría de tener sobre la interpretación de la normativa sobre acceso de los representantes a la información pública ${ }^{2}$. Me planteaba en ellos la posibilidad de una «relectura» de la regulación sustantiva y procedimental contenida en la normativa local a la luz de la nueva normativa general sobre transparencia y acceso a la información. Sintetizando lo entonces expuesto, la exigua legislación estatal básica se contiene en el art. 77 LBRL, desarrollada por la legislación autonómica y en lo no previsto en ésta por los también limitados arts. 14 al 16 ROF. Mi conclusión en estos trabajos era que esta normativa había de ser ahora cohonestada con la normativa sobre transparencia, a partir del principio de que, en ningún caso, los concejales, como representantes de los ciudadanos democráticamente elegidos, podían entenderse situados en una peor condición para acceder a la información municipal que los propios ciudadanos. Esta regla, consideraba y considero, debía proyectarse sobre cualquier interpretación de las reglas establecidas en la LBRL o en el ROF (o en la legislación autonómica respectiva). Por ejemplo:

1 El Consejo de Transparencia y Buen Gobierno estatal (CTBG) fijó su doctrina general en torno a la aplicación de la disposición adicional primera de la Ley 19/2013 sobre regulaciones especiales del derecho de acceso a la información pública en su Criterio interpretativo 8/2015, de 12 de noviembre. Pone de relieve que las únicas excepciones a la aplicación directa de la LTBG son las previstas en la disposición adicional primera, que vincula la aplicación supletoria de la Ley a la existencia de una normativa específica que prevea y regule un régimen de acceso a la información, también específico, en una determinada materia o área de actuación administrativa.

2 "La aplicación de la Ley Andaluza de transparencia en las entidades locales", Revista Andaluza de Administración Pública, núm. 90, 2014, págs. 15-55, en particular págs. 51-55; “La aplicación de la Ley de Transparencia en las entidades locales”, en VILLORIA MENDIETA, M. (dir.), Buen Gobierno, Transparencia e integridad institucional en el Gobierno local, Tecnos-Diputación de Barcelona, Madrid, 2016 (primera edición en catalán, 2015), págs. 105-124, en particular págs. 120-123; o en "Transparencia y acceso a la información en las entidades locales vascas", Revista Vasca de Administración Pública, núm. 107-II, 2017, págs. 469-495, en particular págs. 491-495. 
- Los concejales no han de motivar la solicitud de información, al igual que no tienen por qué hacerlo los ciudadanos, como hemos visto, según la LTBG. Esta era ya la interpretación mayoritaria de la jurisprudencia, que considera que la conexión de la información solicitada con las funciones ha de entenderse implícita ${ }^{3}$.

- Sólo pueden rechazarse peticiones abusivas, lo que debe interpretarse en un sentido muy limitado, como también ha destacado la jurisprudencia ${ }^{4}$, pues el propio art. 18.1.e) LTBG sólo permite la inadmisión, mediante resolución motivada, de las solicitudes que sean manifiestamente repetitivas 0 tengan un carácter abusivo no justificado con la finalidad de transparencia que se persigue.

- La limitación del derecho a obtener copias de la información a una serie de casos tasados o al supuesto en que ello sea expresamente autorizado por el Presidente de la Comisión de Gobierno (léase, Junta de Gobierno Local), establecida en el ROF, resulta muy discutible, pues parece inconsecuente que los ciudadanos tengan derecho a solicitar el acceso mediante envío de copias, de forma gratuita si son en formato electrónico, y se le niegue a sus representantes locales, por lo que esta disposición podría entenderse superada, siempre, claro, que no se ejerza el derecho de forma abusiva pidiendo copias de series documentales extensísimas no justificadas por la finalidad de transparencia, límite que también es válido para los ciudadanos.

- La indefinición sobre los límites al derecho de acceso acompañada de esta libertad de decisión de los Alcaldes o Presidentes colisiona desde luego con los principios elementales de nuestra Constitución (interdicción de la arbitrariedad, reserva de ley para la limitación de los derechos, necesidad de que los posibles límites establecidos por la ley tengan fundamento en preceptos constitucionales y sean proporcionados...). Al respecto, el catálogo de límites establecidos en la LTBG ha de entenderse vigente también en el acceso de los concejales, pues responden a derechos y bienes constitucionales que han de ser compatibilizados con el derecho de acceso. Pero cabe plantearse si respecto de éstos han de jugar de una forma más atenuada, en la medida en que la función política de los concejales conecta directamente con el art. 23.2 CE. En particular, el límite más habitual es el relativo al derecho a la intimidad y a la protección de datos, en los que en síntesis, el principio más general es que cuando se trata de datos personales no especialmente protegidos hay que ponderar el perjuicio que supondría para el afectado su revelación y el interés público para la transparencia (ergo, para la participación y control ciudadanos, en este caso a través de sus representantes) y debe prevalecer, como regla general, cuando sea información directamente atinente a la organización, la actividad o el gasto público. Además, a diferencia de la LTBG, que permite al ciudadano difundir cualquier información que obtengan a través del ejercicio del derecho de acceso (es más, se potencia la publicidad activa por la propia Administración de toda información que haya sido facilitada por esta vía), la normativa local impone a los miembros de la Corporación el deber de guardar reserva en relación con las informaciones que se les faciliten para hacer posible el desarrollo de su función, singularmente de las que han de servir de antecedente para decisiones que aún se encuentren pendientes de adopción, así como para evitar la reproducción de la documentación que pueda serles facilitada, en original o copia, para su estudio. Todo ello lleva a concluir que la protección de datos no puede suponer una «excusa» para ocultar información relevante para el ejercicio de la función del concejal conectada con el art. $23.2 \mathrm{CE}^{5}$.

Todas estas cuestiones me parecían entonces necesitadas de aclaración por cuando se trataba de «reinterpretar» cuestiones reguladas en un sentido más restrictivo a la luz de la jurisprudencia y de la nueva normativa general sobre acceso.

${ }_{3}$ Por todas, SSTS de 26 de junio de 1998, Ar. 6288, de 5 de noviembre de 1999, 2000/2013, o de 27 de noviembre de 2000, 2001/1328.

${ }^{4}$ Por todas, STS de 28 de mayo de 1997, Ar. 4286.

5 En ese sentido, la propia jurisprudencia viene reconociendo el derecho de los concejales (a diferencia del común de los ciudadanos) a acceder a datos del padrón para poder ejercer su labor de control y crítica. Un tanto más restrictiva, como suele ocurrir, es la visión de la Agencia Española de Protección de Datos, que considera que en las transmisiones de información a los concejales hay una cesión de datos (lo que es discutible pues se trata de miembros de la propia corporación y no de terceras personas) y por ende cualquier transmisión debe estar justificada conforme al principio de proporcionalidad (así, en el Informe 0016/2013, en un caso de solicitud de un concejal del acceso a información sobre la identidad de las personas que tienen asignados teléfonos móviles corporativos así como el registro de llamadas entrantes y salientes, considera que la primera es proporcionada pero la segunda no). 
El tema que, sin embargo, ni me planteaba siquiera, era el de la posibilidad de los representantes locales de hacer uso de la nueva vía de garantía del derecho de acceso creada por la normativa sobre transparencia: un recurso ágil, gratuito y eficaz ante una Autoridad independiente especializada. Que una vez creada esta garantía adicional, materias que por su relevancia tenían una regulación previa como el acceso a la información ambiental o el acceso de los representantes políticos a la información se beneficiarían de esa garantía me parecía evidente, y la razón primera de la referencia a la supletoriedad de la normativa general sobre acceso a la información en lo no regulado en la normativa específica que ya se encontraba en el anterior Anteproyecto de Ley del Gobierno socialista y que adoptó también la actual LTBG $^{6}$.

Sin embargo, he asistido con perplejidad a cómo por parte del CTBG y de algunos Consejos autonómicos se ha interpretado que la garantía de la que goza cualquier ciudadano de interponer una reclamación ante las autoridades independientes especializadas les queda vedada, salvo que oculten su condición de representantes políticos y no aludan a su normativa especial, sino a la normativa general sobre acceso a la información. Aún más, alguna autoridad autonómica también inadmite las solicitudes formuladas por los representantes políticos apelando a la normativa general y «ocultos» como ciudadanos de a pie si llega a advertir que primero solicitaron infructuosamente la información en su condición de representantes conforme a la normativa especial. Se les pone de relieve, en ambos casos, que su condición de representantes políticos les impide acudir a esta garantía (rápida, gratuita; eficaz, en suma) pero que, «en compensación», les abre la garantía de los recursos administrativos y contencioso-administrativo por el procedimiento de protección de los derechos fundamentales. Se obvia que estas vías se han revelado ineficientes para posibilitar la función de control y rendición de cuentas de los representantes políticos en la oposición, pues estas funciones exigen inmediatez en la respuesta ${ }^{7}$. No hay mayor prueba de ello que constatar, como veremos, que los representantes políticos no han visto el beneficio de esa "compensación» y se han apresurado a plantear reclamaciones ante las nuevas Autoridades administrativas independientes de garantía del derecho de acceso, obteniendo un resultado dispar, pues otras Autoridades autonómicas, por el contrario, sí han afirmado con rotundidad su competencia.

La perplejidad se acentúa si se tiene en cuenta que, en 2015 (por tanto, ya aprobadas la Ley estatal y buena parte de las Leyes autonómicas de transparencia, pero en el año anterior a los primeros pronunciamientos sobre este tema por parte de las Autoridades de control), el propio Tribunal Supremo aportó una argumentación que por su claridad y rotundidad resultaba esclarecedora, y que, como veremos, ha sido una referencia clave en las resoluciones favorables a admitir las reclamaciones por algunas Autoridades de transparencia y para la doctrina. En efecto, en dos sentencias del mismo día ${ }^{8}$, el Alto Tribunal resolvió sendos recursos interpuestos por parlamentarios autonómicos valencianos ante la negativa del Gobierno de la Generalitat a remitirles documentación relacionada con casos de gran repercusión como la situación financiera y cierre de la radio televisión valenciana o el aeropuerto de Castellón. El Tribunal Supremo enmarcó la solicitud de información en el artículo 23.2 CE y precisó que:

«Y, en cuanto a la posibilidad de que los diputados puedan optar entre seguir la vía ofrecida por el Reglamento de la cámara a la que pertenecen o pedir tutela judicial al derecho que les reconoce y que se integra en las atribuciones propias de su cargo público representativo, hay que recordar que son diversos los supuestos en que los interesados tienen varios caminos a su disposición para buscar la satisfacción de sus pretensiones sin que eso suponga quiebra de

6 En el caso del acceso a la información ambiental se podía aún encontrar un motivo para la duda y no ser pacífico al remitirse expresamente el artículo 20 de su Ley reguladora a las vías generales de recurso, administrativa y contenciosa, como expresé en mi trabajo Transparencia, acceso a la información pública y buen gobierno, Tecnos, Madrid, 2014, págs. 54-55. No obstante, también en este caso expuse de forma razonada y con detalle mi juicio acerca de la pertinencia de la aplicación supletoria de la garantía en un trabajo monográfico, "El acceso a la información ambiental. Relaciones entre normativa general y normativa sectorial. En particular, el sentido del silencio y la garantía de la reclamación ante una autoridad administrativa independiente", Revista Aranzadi de Derecho Ambiental, núm. 33, 2016, págs. 125-162.

7 M. A. BLANES CLIMENT (https://miguelangelblanes.com/2017/02/08/los-concejales-pueden-presentar-la-reclamacion-prevista-en-las-leyes-de-transparencia/) subraya la inutilidad del procedimiento preferente judicial para acceder a la información en un plazo razonable, ya que se trata de un procedimiento preferente en primera instancia, pero no en las posteriores, de tal manera que se puede tardar una media de 2 años en obtener una sentencia firme, a lo que se suma el que tarda la Corporación en facilitar la información, con lo que la información puede no ser ya útil ni de interés. Se le suma el coste económico de abogado, procurador y posible condena en costas si se pierde el litigio.

8 SSTS de 15 de junio de 2015, Ar. 4591 y 4815. 
ningún principio o regla que deban ser observados. Basta con pensar en la posibilidad siempre existente de solicitar la intervención del Defensor del Pueblo o de acudir a vías diferentes de las judiciales para lograr el propósito que se desea. E, incluso, para obtener la tutela judicial hay casos en que son varios los caminos que se pueden emprender como, por ejemplo, sucede cuando cabe ensayar, incluso simultáneamente, el recurso especial para la protección de derechos fundamentales y el ordinario.

Ya al margen de las circunstancias propias de este litigio y como consideración de futuro, hay que decir que, tras la Ley 19/2013, de 9 de diciembre, de transparencia, acceso a la información pública y buen gobierno, y para la Comunidad Valenciana, tras la Ley 2/2015, de 2 de abril, de transparencia buen gobierno y participación ciudadana de la Comunidad Valenciana, el derecho de los parlamentarios a la información pública no puede sino verse fortalecido. En efecto, a fin de que estén en condiciones adecuadas para hacer frente a la especial responsabilidad que se les ha confiado al elegirlos, habrán de contar con los medios necesarios para ello, los cuales en punto al acceso a la información y a los documentos públicos no sólo no podrán ser inferiores a los que tiene ya a su disposición cualquier ciudadano en virtud de esas leyes, sino que deben suponer el plus añadido imprescindible.. ${ }^{9}$.

En estos breves párrafos se sintetizan dos ideas que parecen elementales y básicas: que las vías de protección de los derechos a menudo son diversas y acumulativas, y que los medios de los representantes políticos para obtener información para el desempeño de su tarea de representación política no podrán en ningún caso ser inferiores a los que están a disposición de sus propios representados (como he venido defendiendo desde la aprobación de la LTBG) sino que deben ser superiores.

Pues bien, en las líneas que siguen expondré las resoluciones recaídas sobre este asunto y cuál es mi propia valoración jurídica.

\section{LAS DIFERENTES POSICIONES DE LAS AUTORIDADES INDEPENDIENTES DE TRANSPARENCIA}

En el aún inicial corpus doctrinal de las Autoridades independientes de transparencia, estatal y autonómicas, pueden encontrarse posturas diferentes, que pasamos a sintetizar.

1. La plena libertad de los representantes políticos para determinar el bloque normativo aplicable, con admisión de las reclamaciones sólo en los casos en que se ha invocado expresamente la normativa sobre transparencia, y sin posibilidad de recurrir al «espigueo» para pretender la aplicación de las previsiones más favorables de uno y otro bloque normativo.

La posición del CTBG fue fijada a raíz de una Consulta que le elevó el Consejo de Transparencia murciano. En síntesis, interpreta que ante una solicitud de información formulada por un representante local, son de aplicación alternativa dos bloques normativos: el que regula el derecho de acceso a la información por parte de los representantes locales, en su calidad de tales, con las condiciones procedimentales, sustantivas y de garantías establecidas en la normativa local; y el que regula el derecho de acceso a la información por los ciudadanos, entre los que se encuentran, también, los representantes políticos en su cualidad de ciudadanos, con las condiciones procedimentales, sustantivas y de garantías establecidas en la normativa sobre transparencia. La primera será la vía «habitual y ordinaria», habida cuenta el alcance del acceso y las garantías jurisdiccionales con las que cuenta. El representante local goza de plena libertad para determinar el bloque normativo aplicable, bastándole para ello decidir si actúa como representante político o como ciudadano, y cuál haya sido su decisión se extrae de qué normativa haya invocado. Si actúa como representante político, en definitiva, carecerá de la garantía de la reclamación ante una Autoridad independiente de transparencia ${ }^{10}$.

\footnotetext{
${ }^{9}$ La cursiva es mía.

10 "Consulta sobre aplicación de la Ley 19/2013, de 9 de diciembre, de Transparencia, Acceso a la Información y Buen Gobierno a Concejales", formulada por el Consejo de Transparencia de la Región de Murcia, de 18 de febrero de 2016. El CTBG recuerda que el derecho de acceso a la información por los cargos representativos locales forma parte del derecho fundamental acogido en el artí-
} 
REALA. Nueva Época - N. 8, noviembre 2017 - ISSN: 1989-8975 - DOI: 10.24965/reala.v0i8.10439 - [Págs. 27-48]

El acceso de los representantes políticos a la información y la nueva normativa sobre transparencia y acceso a la información ...

Emilio Guichot

Con posterioridad, ha tenido ocasión de aplicar este criterio al hilo de reclamaciones interpuestas por diversos representantes locales de entidades locales pertenecientes a Comunidades Autónomas que han suscrito convenio con el CTBG para que sea éste el que ejerza la competencia para la resolución de reclamaciones frente a decisiones de sujetos de ámbito autonómico o infra autonómico, todo ello en aplicación de la disposición adicional cuarta de la LTBG.

La aplicación de esta doctrina ha sido la siguiente:

- En las primeras resoluciones dictadas una vez formulado el criterio general, un concejal de un mismo municipio pedía información en representación de su Grupo municipal, sin invocar normativa alguna, a las que el Ayuntamiento no dio respuesta y posteriormente en alegaciones el propio Ayuntamiento manifestó que debían entenderse interpuestas conforme a la normativa local y estimadas por silencio positivo. EI CTBG no inadmitió las reclamaciones, ni las consideró estimadas por silencio, sino que entró a conocer sobre el fondo, en aplicación de la LTBG, para estimarla, en un caso, y desestimarlas, en otros ${ }^{11}$.

- Posteriormente, ha inadmitido las reclamaciones provenientes de solicitudes presentadas por el representante local invocando la normativa local (incluso si el Ayuntamiento las ha tramitado conforme a la LTBG), y admitido las presentadas apelando a la LTBG ${ }^{12}$.

culo 23.2 de la Constitución española y reconocido en el artículo 77 de la LBRL. Su desarrollo corresponde a la normativa autonómica sobre régimen local y, en su defecto, se encuentra en los artículos 14 a 16 del ROF. Este derecho tiene dos vías de protección ordinaria (el recurso potestativo de reposición y el recurso contencioso-administrativo) a las que hay que sumar dos garantías adicionales (el procedimiento para la protección de los derechos fundamentales de la persona regulado en los artículos 114 a 121 LJCA y la vía del recurso de amparo ante el Tribunal Constitucional). Tras la entrada en vigor de la LTBG existen de este modo dos vías en que los concejales pueden ejercer su derecho de acceso. Una la reseñada, que «será la vía habitual y ordinaria de ejercicio del derecho fundamental de referencia debido, sobre todo, tanto al alcance del acceso a la información como a las garantías jurisdiccionales que incorpora», y otra la de la LTBG, conforme a sus reglas y sus propios mecanismos de recurso, incluida la reclamación ante la autoridad independiente.

11 En la Resolución RT 51/2016, de 15 de junio de 2016, se trataba de la solicitud de información acerca del destino de los ingresos obtenidos por el bar ubicado el campo de fútbol municipal, así como de la entrada al campo en los días de competición. La solicitud se presenta sin invocar la normativa de aplicación. Ante la falta de respuesta en el plazo de un mes previsto en la LTBG optó por reclamar ante el CTBG. El Ayuntamiento exponía en sus alegaciones que el solicitante no había invocado la LTBG, sino de su solicitud se deducía que formulaba una pregunta escrita para ser contestada en sesión plenaria en el capítulo de ruegos y preguntas de conformidad con el artículo 97 del ROF. EI CTBG reitera la doctrina antes reproducida y señala que «en cuanto respecta al fondo del asunto planteado hay que partir, para su resolución, del objeto del mismo, así como del objeto de la LTAIBG y de su ámbito subjetivo de aplicación». Constata que los clubes de fútbol no están entre los sujetos obligados por la norma, por lo que desestima la reclamación. Obsérvese, no se inadmite por aplicación de la Disposición adicional primera en el entendimiento dado en la Consulta antes comentada. En la Resolución RT 56/2016, de 15 de junio de 2016, se trataba de la solicitud de información acerca de los ingresos obtenidos en concepto de precio público por las escuelas deportivas municipales en un período determinado. La solicitud se presenta sin invocar la normativa de aplicación. Ante la falta de respuesta en el plazo de un mes previsto en la LTBG optó por reclamar ante el CTBG. El Ayuntamiento exponía en sus alegaciones que el solicitante no había invocado la LTBG, sino de su solicitud se deducía que la formulaba de conformidad con la normativa local, por lo que debió entender la solicitud estimada por silencio. El CTBG se remite a la doctrina reproducida en su Resolución RT 51/2016, de 15 de junio de 2016. Estima que al no haberse aplicado precios públicos y no haber, pues, ingresos, no existía información y por ello objeto sobre el que ejercer el derecho de acceso, por lo que desestima la reclamación. Admitida la reclamación, la respuesta debería haber sido, creemos, otra: que procedía dar la información que en este caso era precisamente que no había ningún ingreso. Finalmente, en la Resolución RT 57/2016, de 20 de junio, se presentaron dos solicitudes de información en relación con dos contratos menores, sin obtener contestación. En las alegaciones, el Ayuntamiento adujo que no se había invocado la normativa de transparencia, por lo que era de aplicación la normativa local y debía entender concedida la información por silencio positivo. EI CTBG alude a sus Resoluciones 51 y 56/2016. Recuerda que la información sobre contratos debe ser objeto de publicidad activa, lo que no obsta para que pueda solicitarse, y declara el derecho a obtenerla estimando la reclamación.

12 En la Resolución RT 71/2016, de 12 de julio de 2016 se trataba de dos solicitudes de información presentadas por un concejal de un ayuntamiento asturiano en relación con dos expedientes administrativos: uno, un plan de carreteras y otro, un expediente de contratación. La solicitud se formula con invocación del ROF. Transcurridos los cinco días a los que se refiere el artículo 14.2 ROF, entendió que se había producido el silencio positivo y acudió a los servicios municipales a consultar el expediente pero se le denegó el acceso, ante lo cual dirigió un escrito al Alcalde invocando la vulneración del artículo 23.2 CE. Finalmente, se le concedió el acceso al plan de carreteras y respecto del expediente de contratación se le dirigió un escrito en el que se le informó de que su solicitud se había tramitado conforme a la LTBG, atendiendo que en otras ocasiones había solicitado información, unas veces como concejal conforme al ROF y otras como ciudadano conforme a la LTBG, al no haber invocado la condición de concejal. Concedido el acceso, el solicitante pidió que la información se le remitiera por correo electrónico y en un plazo de diez días, aplicando lo dispuesto en la LTBG. Ante la falta de contestación a su petición, interpuso reclamación ante el CTBG pidiendo que se ordenara la entrega de la información. EI CTBG invoca sus resoluciones 51 y 56/2016 y reproduce su doctrina general. Considera que las solicitudes se habían formulado en este caso en la condición de concejal y en conclusión «no cabe presentar una solicitud de acceso a la información de acuerdo con un régimen jurídico y tramitarlo en función de las especificaciones de otro régimen jurídico», por lo que inadmite la reclamación. En la Resolución 205/2016, de 2 de noviembre, estima la reclamación del Alcalde-Presidente de la Junta Vecinal de Bolmir (Cantabria) que 
- En sus resoluciones más recientes, en supuestos en que el concejal ha invocado la LTBG y el Ayuntamiento ha alegado que debía aplicarse la normativa local ${ }^{13}$, tras apelar al criterio general antes comentado, ha añadido toda una declaración de principios, en la que pone de relieve la necesidad de determinar el régimen jurídico aplicable «a fin de garantizar la seguridad jurídica y evitar cualquier confusión en el uso de las distintas vías de acceso a la información de que disponen los cargos representativos locales». Y ello por cuanto la vía de la normativa de régimen local y la de la normativa de transparencia «obedecen a lógicas y presupuestos distintos». La primera, a la función de control político en el marco de la democracia representativa, y la segunda a la de control y participación ciudadanos. Cada una de ellas tiene un régimen acabado de procedimiento y garantías procesales y jurisdiccionales, por lo que hay que optar entre ambas, sin que quepa, por parte del representante político solicitante ni de la Administración, recurrir a la técnica del «espigueo» seleccionando la norma más favorable de cada uno de los grupos normativos, todo ello por un principio de seguridad jurídica ${ }^{14}$. De este modo, y en el caso concreto, habiendo invocado el solicitante la LTBG, admite las reclamaciones y aplica ésta y no la normativa local.

Alguna Autoridad autonómica han asumido la doctrina estatal acríticamente, sin aportar un razonamiento propio. Es el caso de la Comisión de Transparencia de Castilla y León, cuyas resoluciones se remiten a la doctrina del CTBG estatal, con expresa alusión a la respuesta que dio a la Consulta 105/2015, de 18 de febrero, y que antes expusimos, y precisan que sólo será de aplicación la normativa sobre transparencia en el caso en que así se indique expresamente en la solicitud ${ }^{15}$.

previamente había realizado una solicitud de información con invocación de la LTBG ante el Ayuntamiento de Campoo de Enmedio sobre una subvención para una fiesta vecinal, sin obtener contestación alguna. En la Resolución 282/2016, de 20 de diciembre, presenta la reclamación un vocal de la junta vecinal que había invocado en su solicitud la normativa local, lo que hace la que el CTBG inadmita su reclamación.

${ }^{13}$ Las Resoluciones RT 192, 194, 195, 196 y 201/2016, de 5 de diciembre de 2016, 198/2016, de 7 de diciembre, 202/2016, de 16 de diciembre, 193, 197/2016, de 27 de diciembre, 199, 200 y 203/2016, de 28 de diciembre, 216/2016, de 17 de enero de 2017 , comparten el supuesto de un mismo concejal que remite un escrito a un Ayuntamiento apelando a la LTBG y solicitando diversa información. Ante la falta de respuesta en el plazo de un mes, presenta reclamación ante el CTBG. En las alegaciones el Ayuntamiento aducía que la normativa de aplicación era la de régimen local y que la información solicitada era irrelevante para el control y fiscalización de la actuación municipal puesto que no iban a ser objeto de votación alguna, aparte de que sería una solicitud abusiva porque paralizaría el funcionamiento municipal.

${ }_{14}$ Ambas vías, a pesar de compartir un vínculo común con la cláusula de Estado democrático ex artículo 1.1 de la Constitución, obedecen a lógicas y presupuestos distintos. Por una parte, la vía de acceso a la información contemplada en la legislación de régimen local -Ley 7/1985, de 2 de abril, reguladora de las Bases del Régimen Local, legislación autonómica de desarrollo y artículos 14 a 16 del Real Decreto 2568/1986, de 28 de noviembre, por el que se aprueba el Reglamento de Organización, Funcionamiento y Régimen Jurídico de las Entidades Locales- se enmarca en la función de "control político» que corresponde al binomio minoría que controla/mayoría que gobierna derivada del principio representativo. Esto es, la idea de control llevado a cabo a través de la minoría en la asamblea representativa local -el pleno municipal- se ubica en la democracia constitucional en un sistema que pretende, entre otras cuestiones, construir la representación política mediante el juego de los principios de transparencia, rendición de cuentas y responsabilidad de los poderes públicos en el ejercicio de sus funciones. Por otra parte, la vía del acceso a la información contemplada en la LTAIBG se enmarca en el binomio ciudadano/gobierno y administración, configurándose tal vía de acceso como un derecho en virtud del cual «los ciudadanos pueden conocer cómo se toman las decisiones que les afectan, cómo se manejan los fondos públicos o bajo qué criterios actúan nuestras instituciones» a fin de, por un lado, someter a escrutinio ciudadano a los responsables públicos, según se proclama en el preámbulo de la LTAIBG y, por otro lado, formar y construir un conocimiento cabal y completo de los asuntos públicos que es permita formar una opinión y participar en el juego político a través de su intervención en los procesos electorales. Tomando en consideración la distinta naturaleza de tales vías cabe advertir que ambas disponen de un régimen jurídico completo y acabado caracterizado por la regulación de un procedimiento de ejercicio del derecho de acceso -solicitud, plazos, formalización del acceso, etc.- y la previsión de diferentes técnicas para garantizar el ejercicio del derecho de acceso que incorporan -garantías procesales y jurisdiccionales-. De este modo, este Consejo considera que no resulta posible acudir por el ciudadano o por la administración a la técnica del «espigueo» consistente en seleccionar las normas más favorables de distintos cuerpos normativos para dotarse, así, de un régimen jurídico ad hoc y desvinculado de los cauces legalmente establecidos para la creación de un derecho. Entre otros fundamentos de tal aseveración se encuentra la garantía del principio de seguridad jurídica, principio que se entiende como la certeza sobre el ordenamiento jurídico aplicable y los intereses jurídicamente tutelados, procurando «la claridad y no la confusión normativa», así como «la expectativa razonablemente fundada del ciudadano en cuál ha de ser la actuación del poder en la aplicación del Derecho. -SSTC 46/1990, de 15 de marzo, F. J. 7, de 14 de febrero, F. J. 5; y 37/2012, de 19 de marzo, F. J. 8, entre otras-».

${ }_{15}$ Así, en las Resoluciones 12 y 13/2016, de 9 de junio, se ventilan dos reclamaciones que traen causa de sendas solicitudes de un Vocal de una Junta Vecinal ante el órgano de gobierno de esta entidad local menor, pidiendo el acta de una sesión y una copia de la grabación, en la primera, y los criterios para el otorgamiento de beneficios a vecinos, en la segunda. La Comisión constata que la petición se realizó en calidad de vocal sin señalar que se optaba por realizar la petición por la vía de la normativa de transparencia, por lo que se aplica el régimen de la legislación local y, por ello, inadmite la reclamación. En la Resolución 21/2016, de 21 de julio y la 25/2016, de 8 de agosto, concejales de un grupo municipal piden información diversa apelando a la normativa local y reclaman por 
Paradójicamente, la Autoridad murciana, que formuló la consulta que dio origen al establecimiento de la doctrina comentada, la ha aplicado en sentido contrario, admitiendo su competencia para conocer de las reclamaciones relativas a solicitudes formuladas conforme a la normativa local ${ }^{16}$.

\section{Una vuelta de tuerca: la limitación de la posibilidad del representante político para acogerse a la normativa general y la consiguiente inadmisión de las reclamaciones cuando antes se solicitó la misma información en calidad de representante político}

El Consejo de Transparencia y Protección de Datos de Andalucía (CTPDA) ha dado un paso más, endureciendo la doctrina estatal. Si ésta parte de la libertad de determinación por el representante político del bloque normativo aplicable, para el Consejo andaluz hay una limitación a dicha libertad, conforme a la cual éste no puede solicitar por la vía de la normativa la información que no obtuvo por la vía de la normativa local o de las peticiones de información a través de la Mesa del Parlamento, en el caso de los parlamentarios autonómicos. Y ello, incluso, si la no obtención no fue debida a la concurrencia de un límite legal, sino a la falta de contestación.

EI CTPDA se acercó por primera vez al tema en su respuesta a la Consulta 1/2016, de 11 de mayo de 2016, formulada por un Ayuntamiento, sobre la procedencia de dar información a un concejal sobre las ayudas sociales percibidas por los demás concejales del municipio en cuestión. Se trataba de una cuestión sobre el límite derivado de la protección de datos, pero para resolverlo el CTPDA consideró necesario cuestionarse previamente si las solicitudes de información de los concejales a sus órganos de gobierno están sujetas a la normativa sobre transparencia y, en relación a este tema, cuál es el alcance de la remisión a la normativa específica y a la supletoriedad de la normativa sobre transparencia. Nótese que el Consejo andaluz evacúa su consulta poco tiempo después de que el Consejo estatal haya fijado su doctrina en su respuesta a la Consulta de 18 de febrero de 2016. El CTPDA recuerda el contenido de la normativa estatal sobre acceso a la información por los representantes locales. Aprecia que la remisión a regímenes jurídicos específicos se refiere a «materias» («un criterio estrictamente objetivo o material») y no a sujetos, como ocurriría con los concejales, interpretación abonada por una interpretación sistemática de la propia normativa sobre transparencia, «que en ningún caso prevé una restricción o matización del derecho de acceso a la información pública de índole personal o subjetiva». Concluye que los concejales tienen una doble vía, la de la normativa local, que sería la «habitual y ordinaria» por cuanto cuenta con mayor garantía judicial y no está sometida a las restricciones de la normativa sobre transparencia, y ésta segunda, como ciudadanos que son, con la posibilidad de formular en este caso reclamaciones ${ }^{17}$.

haber obtenido sólo información oral. La Comisión inadmite la reclamación habida cuenta de que las solicitudes fueron presentadas en la condición de concejales y con invocación de la normativa local. En la Resolución 30/2016, de 7 de septiembre, un concejal pide información, identificándose en su condición de tal. La denegación apela a la normativa local. La Comisión considera que las solicitudes fueron realizadas en la condición de concejal, sin que el solicitante hubiera señalado que se optaba por realizar la petición de información al amparo de lo dispuesto en la LTBG, por lo que inadmite la reclamación. En la Resolución 61/2016, de 13 de diciembre, cuatro concejales del mismo grupo municipal, incluido su portavoz, solicitan información de gastos e ingresos de las piscinas municipales. La Comisión constata que las solicitudes fueron realizadas en la condición de concejales, sin que se señalara que se optaba por realizar la petición al amparo de la ley de transparencia y por ello inadmite la reclamación.

16 Resoluciones 30 y la 36/2015, de 17 de mayo, que estiman sendas reclamaciones.

17 «A la vista de estas consideraciones, y a fin de hallar una lectura integradora de los diversos preceptos en juego, cabe llegar a la conclusión de que el régimen de acceso previsto específicamente por la normativa local no rige de forma única y exclusiva en este ámbito -lo que conllevaría el consiguiente desplazamiento de la LTPA-, y por tanto que no está completamente cerrada a los miembros de las corporaciones locales la fórmula del derecho de acceso ex legislación de transparencia, sin que en modo alguno ésta quede limitada a operar como mero derecho supletorio. Así pues, desde la entrada en vigor de esta legislación, los cargos públicos representativos locales tienen a su disposición dos vías alternativas para canalizar las peticiones de información a los órganos de gobierno. De una parte, en su condición de cargo público, a través de la normativa de régimen local (art. 77 LrBRL y arts. 14-16 ROF), en la que se plasmaría el derecho fundamental ex art. 23.2 CE y, consecuentemente, permitiría acudir al procedimiento preferente de tutela de los derechos fundamentales (arts. 114-121 de la Ley 29/1998, de 13 de julio, reguladora de la jurisdicción contenciosoadministrativa) y, en última instancia, interponer el recurso de amparo ante el Tribunal Constitucional. O bien, en cuanto ciudadanos, pueden ejercitar el derecho de acceso a la información pública regulado en el art. 24 y siguientes de la LTPA, en cuyo caso, obviamente, podría interponerse ante este Consejo con carácter potestativo la correspondiente reclamación (art. 33 LTPA). La primera de las mencionadas puede considerarse la vía habitual y ordinaria a seguir por los concejales, pues, además de ejercerse a través de ella el repetido derecho fundamental con la aplicación de las correspondientes garantías jurisdiccionales, conduce a un régimen de acceso más amplio en cuanto no está sujeto a las específicas restricciones establecidas en la legislación de transparencia en relación con las solicitudes de información.». 
Posteriormente se ha enfrentado al tema en diversas resoluciones.

- En la primera de ellas, el asunto trae causa de una solicitud de información por un concejal actuando como tal, reconducida por el Ayuntamiento a la normativa sobre transparencia. El propio concejal alegaba que interponía reclamación siguiendo el pie de recurso pero que consideraba aplicable la normativa local. El CTPDA parte de su criterio en la Consulta antes expuesto y estima que la elección del bloque normativo efectuada por el solicitante vincula a la Corporación, y por tanto, no puede aplicársele causas de inadmisión de la normativa sobre transparencia. Lo curioso del caso es que, de forma incoherente con su criterio general, y siendo la normativa aplicable la LBRL y el ROF, el CTPDA no inadmite la reclamación sino que la estima, retrotrayendo, por así decirlo, las actuaciones ${ }^{18}$.

- En la segunda y en la tercera, el concejal había pedido información como cargo público utilizando un papel con el membrete oficial del Grupo municipal, sin aludir a la normativa de aplicación, en el primer caso, y aludiendo a la normativa local, en el segundo. EI CTPDA se remite a la Consulta y a la anterior resolución e insiste "en lo determinante que resulta evitar toda posible ambigüedad o confusión en torno a la vía que el interesado quiere realmente transitar», advertencia dirigida a los solicitantes. En ambos casos, se considera que se había solicitado información como concejal conforme a la normativa local y se inadmite la reclamación ${ }^{19}$.

- En la cuarta, el concejal había invocado la normativa autonómica de transparencia y pedía información sujeta, de hecho, a publicidad activa. Previamente había solicitado la misma información invocando la vía local, sin obtener copia de la información sino sólo posibilidad de consulta in situ $^{20}$. EI CTPD apela a la Consulta 1/2016, y a las Resoluciones 56 y 82/2016. Recuerda que

18 Resolución 56/2016, de 13 de julio, un concejal solicita información en materia de nóminas, «en lo que la legislación me ampara como representante público y a los efectos de la labor del control del equipo de gobierno». El Alcalde inadmitió la solicitud más de cinco meses más tarde de su presentación amparándose en la causa de inadmisión de necesidad de previa reelaboración de la Ley de Transparencia y dando como pie de recurso la reclamación potestativa ante el CTBG o en su caso ante el Consejo de Transparencia autonómico ( $\mathrm{sic}$ ). Casi tres meses más tarde, el Concejal interpuso reclamación, en la que hacía valer que la normativa aplicable era la normativa local y que no cabía acudir ante el Consejo de Transparencia, lo que hacía sólo «por indicación puesta al pie de la notificación». En sus alegaciones, el Ayuntamiento alegaba, además, que «tampoco queda suficientemente justificada la finalidad legítima de control de gobierno que pretende ejercer el Concejal solicitante» con base en el art. 77 de la LRBRL, «teniendo en cuenta que la información que solicita se refiere a situaciones laborales y retribuciones de personal de años atrás y firmes». El CTPDA retoma aquí la Consulta 1/2016, de 11 de mayo. Y extrae como conclusión la siguiente: «Ahora bien, una vez que el cargo representativo local en cuestión ha optado por uno de los referidos bloques normativos que permiten su acceso a la información obrante en su Corporación, esta elección vincula al órgano de gobierno, el cual debe, en consecuencia, aplicar en su integridad dicho grupo normativo, sin que en ningún caso quede a su disposición recurrir, a su albur, al sistema de límites o al régimen de garantías propios del bloque normativo que el solicitante declinó seguir. Tiene, pues, razón el ahora reclamante cuando sostiene que, en la medida en que su petición de información la realizó en su condición de cargo público y en ejercicio del derecho fundamental ex art. $23 \mathrm{CE}$, la misma debe sustanciarse de conformidad con lo previsto en la LRBRL y en el ROF y, por tanto, que su solicitud no puede ser inadmitida a trámite por el Ayuntamiento de San Roque (Cádiz) con base en una causa de inadmisión propia de la legislación en materia de transparencia».

19 En la Resolución 82/2016, de 3 de agosto, se trata de la solicitud de información por un concejal ante el mismo Ayuntamiento de San Roque sobre datos laborales de un trabajador de una empresa municipal. Se le denegó arguyendo protección de datos personales, con invocación del ROF. EI CTPDA se remite a la Consulta 1/2016 y a la Resolución 56/2016. Destaca, en línea con la Resolución 56/2016, que una vez que el cargo representativo opta por uno de los referidos bloques, la elección vincula tanto al órgano de gobierno como al representante local, debiendo en lo sucesivo aplicarse en su integridad dicho grupo normativo, «sin que en ningún caso quede a disposición de las partes recurrir al sistema de límites o al régimen de garantías propios del bloque normativo que el solicitante declinó seguir inicialmente. Y habida cuenta de que la conformación del derecho a la información es muy diferente en los reiterados bloques normativos, al diferir en cuestiones esenciales tales como el trámite de admisión, el sistema de límites y el régimen de recursos, huelga insistir en lo determinante que resulta evitar toda posible ambigüedad o confusión en torno a la vía que el interesado quiere realmente transitar». En este caso la petición se hizo en la condición de cargo público -en papel con el logotipo y el membrete del partido y haciendo constar la condición de concejal, sin invocar la Ley de Transparencia- y se canalizó por la legislación de régimen local -en la reclamación sí se alude a la Ley de Transparencia estatal pero también al ROF y se habla del control "político y jurídico»-. El Ayuntamiento, por ello, la tramitó correctamente por la legislación local y, por ende, las vías de recurso son las ordinarias y no cabe reclamación ante el Consejo de Transparencia autonómico, por lo que se inadmite la reclamación. En la Resolución 86/2016, de 7 de septiembre, un concejal solicita información sobre contratación laboral por el Ayuntamiento, invocando la LBRL y el ROF. EI CTPDA apela de nuevo a la Consulta 1/2016 y a las Resoluciones 56 y 82/2016 y se alude a «lo determinante que resulta evitar toda posible ambigüedad o confusión en torno a la vía que el interesado quiere realmente transitar». Por ello, habiendo invocado la normativa local y sólo en la reclamación la Ley de Transparencia, se inadmite la reclamación.

${ }^{20}$ Resolución 89/2016, de 14 de septiembre. El concejal solicitó copia de un informe de auditoría externa sobre la gestión y las finanzas del Ayuntamiento de El Ejido, invocando la Ley autonómica de transparencia y la obligación de publicidad activa de ese tipo de informes. Se le ofrece consulta in situ. En las alegaciones el Ayuntamiento manifestó que la solicitud era reiteración de otra presen- 
en las resoluciones más recientes ha puesto el acento en la necesidad de que se evite cualquier posible confusión o ambigüedad en la utilización de las dos referidas vías alternativas ${ }^{21}$. Añade ahora que «la conveniencia de rehuir todo atisbo de ambigüedad o confusión en el empleo de las reiteradas vías alternativas responde asimismo a exigencias de orden institucional», que se traducirían en la necesidad de evitar a toda costa que el derecho de acceso de la normativa sobre transparencia sea utilizado por el representante público como vía de ejercer su control político que no pudo llevar a cabo a través del cauce ad hoc ${ }^{22}$. En el caso en cuestión, estima que no se aprecia ningún motivo que induzca a confusión: tanto en la solicitud dirigida al Ayuntamiento como en la reclamación presentada ante este Consejo, el solicitante fundamentó su petición única y exclusivamente en la legislación de transparencia y a este marco normativo ciñó toda su argumentación. De hecho, ni siquiera mencionó en dichos escritos que había recabado la información con base en la legislación de régimen local. La solicitud, considera, se presentó, pues, enteramente desvinculada de la anterior petición de información que el reclamante había formulado en ejercicio de su derecho fundamental al ejercicio del cargo público derivado del art. 23.2 CE. Admite, pues, la reclamación, si bien considera que es de aplicación el límite de la prevención, investigación y sanción de los ilícitos penales y que se actuó de forma proporcionada al facilitar la vista de la información pero no su copia. Es decir, la admisión careció, en fin, de consecuencias favorables para el solicitante.

- Las posteriores resoluciones tienen como protagonista no a un representante local, sino autonómico. Se trataba de una parlamentaria del grupo mayoritario de la oposición que solicita información sobre temas de la máxima repercusión política, mediática y judicial relacionado con presuntos casos de corrupción que afectan a la Administración autonómica (ERES y cursos de formación). Formuló la solicitud conforme a la normativa de transparencia y la presentó a través del Portal de Transparencia autonómico. La Consejería afectada decretó la ampliación del plazo para resolver, habida cuenta de la complejidad y el volumen de la información solicitada y, no obstante, tampoco resolvió en el plazo ampliado de tal forma que la parlamentaria interpuso reclamación, en la que expuso que previamente había tratado de obtener la información por diversas vías parlamentarias, sin obtener respuesta pese al compromiso del Gobierno andaluz de facilitarla. Solicitó además que se ordenara la incoación de procedimientos disciplinarios y sancionadores, como prevé la normativa autonómica en caso de falta de resolución en plazo ${ }^{23}$. La Administración no alegó en

tada con base en los artículos 23 CE, LBRL y ROF, que se desestimó dando la posibilidad de consulta in situ. Además, argumentó esa desestimación en el límite de la protección de datos y, añadió, apelando ya a la Ley de Transparencia autonómica, que estaba en juego el carácter reservado de las diligencias sumariales a las que se había incorporado dicho informe por lo que ponderando se había otorgado el acceso habida cuenta de la condición de concejal pero con denegación de la entrega en formado digital o papel. Un resumen ejecutivo de este informe se había puesto a disposición del público en la web municipal.

21 Aquí trae a colación las Resoluciones 82 y 86/2016.

22 «Pero, de otra parte, la conveniencia de rehuir todo atisbo de ambigüedad o confusión en el empleo de las reiteradas vías alternativas responde asimismo a exigencias de orden institucional. Frente a la legislación de régimen local, en la que el derecho al acceso a la información se regula como integrante del derecho fundamental al ejercicio del cargo público representativo $-y$, por tanto, se desenvuelve en el marco de las relaciones políticas e institucionales entre éste y el gobierno municipal-, el derecho conformado en la legislación de transparencia responde a una diferente finalidad institucional, por cuanto se dirige a los ciudadanos en general al objeto de que "puedan juzgar mejor y con más criterio la capacidad de sus responsables políticos y decidir en consecuencia" (Preámbulo de la LTAIBG, apartado I). Se trata este último, pues, de un derecho ajeno a la función de control político que a los concejales corresponde ejercer sobre la acción de gobierno. Por consiguiente, so pena de distorsionar el entero sistema institucional, el derecho de acceso a la información pública configurado en la legislación de transparencia no debe ser instrumentalizado a modo de fórmula para prolongar o extender artificialmente las vías de control político del gobierno municipal por parte de los concejales. En suma, como adelantamos, también por razones de índole institucional, el concejal que, en su condición de ciudadano, decida canalizar su petición de información a través de la LTPA, ha de evitar toda ambigüedad que pueda hacer entender que la misma se despliega en el ámbito de las relaciones políticas entre los cargos electos locales y los órganos de gobierno municipal.».

${ }^{23}$ Resoluciones 96 y 97/2016, de 19 de octubre de 2016, conocen la reclamación de una Parlamentaria andaluza, que formuló su solicitud a través del Portal de Transparencia de la Junta de Andalucía, en relación, en el primero de ellos, con el dinero recuperado de subvenciones al programa de formación profesional para el empleo (en ejecución de las resoluciones de reintegro por importe de 72 millones de euros), y en el segundo, respecto el dinero reclamado y recuperado de los Expedientes de Regulación de Empleo. Ambas solicitudes se dirigieron a la Consejería de Hacienda y Administración Pública, como responsable del control de ingresos pero se redirigieron por ésta a la Consejería de Empleo. Ésta acordó prorrogar el plazo para resolver, «debido al volumen y complejidad de la información solicitada», pero no resolvió siquiera en el plazo prorrogado al doble. En la reclamación, la solicitante expone que se trata de una persistencia en la denegación de información, puesto que la había solicitado también desde un año antes en sede parlamentaria con una proposición no de Ley que había culminado con el compromiso expreso del Gobierno andaluz de ofrecer la información, que no se cumplió. Tampoco la había obtenido en las comparecencias parlamentarias de los Consejeros de Hacienda y de 
ningún momento la incompetencia del CTPDA. Sin embargo, éste se lo plantea motu proprio ${ }^{24}$. El CTPDA acude al Reglamento del Parlamento autonómico, que prevé diversos cauces para solicitar información en el marco del control político. Reconoce a continuación que conforme a su doctrina elaborada respecto de los concejales, que cabe proyectar a este supuesto mutatis mutandi, el cargo político puede también actuar por la vía de la normativa de transparencia «en su condición de simple ciudadano». Trae a colación al respecto la doctrina que hemos venido exponiendo, establecida en la Consulta y precisada en las anteriores resoluciones, incluyendo la necesidad de evitar toda ambigüedad y confusión ${ }^{25}$. El salto respecto de ellas es que aquí se inadmite la reclamación pese a haber presentado la solicitud conforme a la normativa de transparencia, sin ambigüedad alguna por la vía del Portal de Transparencia autonómico. Es el dato de haber acudido previamente sin respuesta a la vía parlamentaria, expuesto por la propia solicitante en sus alegaciones para justificar el porqué de su posterior uso de la vía general, el que se utiliza argumentalmente para inadmitir la solicitud, de tal modo que, y he aquí el salto, la proscripción de ambigüedad ya no se predica de la normativa invocada por el solicitante, como hasta ahora, sino que el haber acudido previamente a la vía de acceso a la información como representante político (la «habitual y ordinaria», en palabras del propio Consejo, y supuestamente más garantista), sin resultados, por un reiterado incumplimiento de la obligación de dar información necesaria para el control político, lo que se convierte ahora en un impedimento para el ejercicio del derecho de acceso a la información que al representante político le está abierto, como a cualquier persona -nacional o extranjero,

\footnotetext{
Empleo, ni en el control ordinario ni en la correspondiente Comisión de Investigación ni en las solicitudes de información presentadas como Parlamentaria a través de la Mesa del Parlamento. En la segunda solicitud añadía que «siendo consciente de que ese Consejo de Transparencia carece de competencias sobre la falta de información del Parlamento de Andalucía, estos hechos circunscritos a la labor parlamentaria de la recurrente se detallan brevemente como complemento a la circunstancia de la imposibilidad de acceder por ninguna vía a la información solicitada [...] Estas dificultades han hecho que tuviera que acudir al portal de transparencia de la Junta de Andalucía para obtener, lamentablemente, otra negativa más al acceso a la información requerida». Solicitaba que se ordenara a la Junta de Andalucía que contestara la solicitud y se incoaran expedientes disciplinarios y sancionadores conforme a la Ley autonómica de Transparencia. En ambos casos, en las alegaciones, el órgano competente de la Consejería de Empleo adjuntó una resolución de inadmisión -dictada una vez recibida notificación del CTPDA para la presentación de alegaciones- por la que se inadmite la solicitud al requerir de una acción previa de reelaboración, alegando incluso la obligación, contemplada en la Ley autonómica, de «realizar el acceso a la información de forma que no se vea afectada la eficacia del funcionamiento de los servicios públicos, concretándose lo más posible la petición» (pese a que como se indicó la solicitud era manifiestamente concreta). A lo que añadía que la inadmisión se llevaba a cabo sin perjuicio de que pudieran concurrir límites al derecho de acceso. Dos meses más tarde, se remitió un informe complementario -la resolución no precisa quién lo emitió- dando cuenta de la comparecencia de la Consejera de Hacienda y Administración Pública en Comisión parlamentaria, a la que asistió la solicitante, ofreciendo información de las sumas recaudadas en los cursos de formación y asimismo, días más tarde, un escrito del Secretario General de Empleo, en el que se adjuntaba la notificación a la solicitante del informe complementario, con el que se daba «respuesta a su solicitud de acceso a la información pública». Respecto de los ERES, la Consejera informó que no tenía la información que se le pedía por cuanto se trataba de procedimientos en los que intervenía también la Agencia estatal tributaria.

24 «Esta reclamación presenta una singularidad que exige que nos planteemos, como cuestión previa, la propia aplicabilidad de la legislación de transparencia al supuesto sometido a nuestra consideración. De esto tendremos ahora que ocuparnos. Ésta es, en efecto, la primera vez que se suscita ante nosotros un caso relativo a una petición de información formulada por un miembro del Parlamento que reproduce una cuestión que ya había dirigido al Gobierno en ejercicio de sus funciones parlamentarias. En consecuencia, el interrogante previo que hemos de resolver estriba en determinar si resulta de aplicación al presente supuesto lo previsto en el segundo apartado de la Disposición adicional cuarta de la LTPA; precepto que reproduce literalmente el segundo apartado de la Disposición adicional primera de la LTAIBG.».

${ }_{25}$ Considera que «por obvias razones, este criterio doctrinal acuñado en el marco de las Corporaciones locales resulta, si cabe, aún más clara y estrictamente aplicable cuando se proyecta al ámbito parlamentario», pues «a este respecto, no debe soslayarse que el Tribunal Constitucional ha destacado el carácter autónomo de la esfera propia de las relaciones políticas entre Ejecutivo y Legislativo cuando ha tenido que resolver recursos de amparo planteados frente a la falta de contestación o la respuesta insatisfactoria por parte del gobierno de peticiones de información efectuadas por parlamentarios», lo que apoya en cita de dos sentencias del Tribunal Constitucional de principios de los noventa que inadmiten sendos recursos de amparo considerando que se vulnera el derecho a la tutela judicial efectiva la inadmisión por el Tribunal Supremo en los años ochenta de los recursos interpuestos por parlamentarios a los que se les denegó información (SSTC 196/1990, de 29 de noviembre y 220/1991, de 25 de noviembre). El argumento probablemente no es afortunado, por cuanto se trata de sentencias anteriores a la Ley 29/1998, de 13 de julio, de la Jurisdicción contencioso-administrativa que prevé expresamente en su artículo 2.a) la protección jurisdiccional de los derechos fundamentales, «todo ello en relación con los actos del Gobierno o de los Consejos de Gobierno de las Comunidades Autónomas, cualquiera que fuese la naturaleza de dichos actos» y, es más, como veremos con detalle más adelante, el propio Tribunal Supremo ha insistido en la idea de la protección reforzada del derecho de acceso a la información de los parlamentarios autonómicos, precisamente por su vinculación con el artículo 23 CE, en su Sentencia de 15 de junio de 2015, Ar. 4815. Es más, tanto el CTBG estatal como el CTPD de Andalucía parten de que el derecho a la información de los representantes políticos goza de la protección judicial preferente y sumaria como un plus añadido a la protección judicial del derecho a la información del común de los ciudadanos...
} 
REALA. Nueva Época - N. 8, noviembre 2017 - ISSN: 1989-8975 - DOI: 10.24965/reala.v0i8.10439 - [Págs. 27-48]

El acceso de los representantes políticos a la información y la nueva normativa sobre transparencia y acceso a la información ...

Emilio Guichot

pública o privada, física o jurídica, ni siquiera necesariamente ciudadano- por la normativa sobre transparencia ${ }^{26}$. Inadmite, en fin, la reclamación ${ }^{27}$.

- La última de las reclamaciones sobre este tema resuelta por el CTPDA a la hora de redactar estas líneas tiene como presupuesto la solicitud de información de un concejal, realizada primero verbalmente en el Pleno y posteriormente, a instancias del Alcalde, por escrito, con la firma de los tres concejales del grupo municipal. Se tramitó por el Ayuntamiento conforme a la normativa sobre transparencia, si bien en realidad se consideró que no se trataba de información pública a los efectos de esta normativa. Reclamó entonces ante el CTPDA ${ }^{28}$. Sin que el Ayuntamiento lo hubiera alegado,

26 «Tras el examen de las circunstancias concurrentes en el presente caso, no puede sino llegarse a la conclusión de que con la solicitud de información formalmente presentada al amparo de la LTPA no se pretendía sino proyectar, prolongar o extender artificialmente a un ámbito institucional ajeno la función de control político del gobierno que corresponde a la ahora reclamante en cuanto miembro del Parlamento.». Las circunstancias en cuestión son las infructuosas actuaciones precedentes y coetáneas de la diputada para obtener la información en vía parlamentaria, manifestadas por la propia reclamante en su escrito de reclamación: «Así se desprende ya del propio escrito de reclamación, en donde se revela explícitamente que la presentación de la solicitud responde a la ineficacia mostrada por las diversas iniciativas que había emprendido la solicitante en su condición de Diputada del Parlamento de Andalucía para acceder a la información pretendida; fundamentalmente, una Proposición no de Ley en Comisión, que fue aprobada el 10 de marzo de 2016, y diversas comparecencias sustanciadas en sede parlamentaria de la Sra. Consejera de Hacienda y Administración Pública y del Sr. Consejo de Empleo, Empresa y Comercio (véase Antecedente $4 .^{\circ}$ ). Si esta circunstancia ya pone de manifiesto una inadecuada utilización del derecho de acceso ex art. 24 LTPA ajena a su finalidad institucional, por cuanto la solicitud vendría a insertarse como un elemento más en la actuación de control del gobierno, otros factores no vienen sino a ratificar esta apreciación. Pocos días antes de que formulara la solicitud de información que está en el origen de esta reclamación (15 de mayo), la solicitante había presentado una iniciativa parlamentaria que tenía por objetivo recabar la misma información ( 9 de mayo) y que sería admitida a trámite por la Mesa del Parlamento el día 11 de mayo, a saber, una pregunta oral en Comisión dirigida a la Consejería de Hacienda y Administración Pública (BOPA, núm. 233, de 23 de mayo de 2016, pág. 41). Y ese mismo día 9 de mayo el Grupo Parlamentario al que pertenece la ahora reclamante había asimismo registrado una solicitud de comparecencia ante la Comisión de Hacienda y Administración Pública de la Consejera de Hacienda y Administración Pública relativa al mismo asunto (BOPA, núm. 231, de 19 de mayo de 2016, pág. 92). Así pues, la reclamante recurrió a la legislación de transparencia cuando aún no habían podido sustanciarse las referidas iniciativas parlamentarias, provocando así que se mantuvieran simultáneamente abiertas las dos vías alternativas de acceso a la información cuya estricta separación venimos sosteniendo en nuestras Resoluciones. Y una vez presentada la solicitud de información, formularía más preguntas relativas al reintegro de las reiteradas subvenciones, que serían admitidas a trámite por la Mesa del Parlamento los días 22 de junio y 6 de julio de 2016 (BOPA, núm. 263, de 5 de julio de 2016, pág. 90 y BOPA, núm. 269 de 15 de julio de 2016, pág. 10, respectivamente). Pero es que, además, cuando ya se encontraba en tramitación esta reclamación (presentada el 22 de julio), la solicitante registraría el 31 de agosto una pregunta para respuesta oral en Pleno «relativa al importe recuperado de expedientes de reintegro de subvenciones de formación profesional para el empleo», que fue admitida a trámite por la Mesa del Parlamento el día 1 de septiembre (BOPA, núm. 296, de 7 de septiembre de 2016, pág. 43). Pregunta que sería respondida por el titular de la Consejería de Empleo, Empresa y Comercio en sesión plenaria celebrada el 8 de septiembre, en donde ofrecería el dato del que disponía "a día de hoy» (DSPA núm. 51 , de 8 de septiembre de 2016, pág. 77). Se produjo, en suma, la mixtura o yuxtaposición de ambos regímenes jurídicos de acceso a la información, que era precisamente lo que trataba de evitar el legislador con el segundo apartado de la Disposición adicional cuarta de la LTPA. Por lo demás, de los perturbadores efectos que esta práctica genera en el conjunto del sistema ya advierte lo sucedido en este caso: como ya señalamos arriba, el 15 de septiembre, cuando todavía se hallaba en tramitación esta reclamación, se sustanció la citada comparecencia de la titular de la Consejería de Hacienda y Administración Pública ante la Comisión, a la que asistió la reclamante en representación de su Grupo Parlamentario, en donde la Consejera ofreció los datos a los que ésta pretendía acceder con la solicitud de información que nos ocupa (véase Antecedente $8 .^{\circ}$ ). Y a raíz de esta comparecencia el titular de la Consejería de Empleo, Empresa y Comercio ha dado respuesta a las diversas preguntas formuladas por la ahora reclamante sobre este asunto que aún se encontraban pendientes de contestación, remitiéndose precisamente a la información suministrada por la Consejera de Hacienda ante la Comisión (BOPA, núm. 315, de 4 de octubre de 2016, págs. 5, 6, 7, 15 y 18). El presente caso ejemplifica, pues, con toda evidencia, la necesidad de que el cargo público representativo que decida canalizar su petición de información a través de la LTPA -actuando, por tanto, como simple ciudadano- eluda cualquier confusión que pueda hacer entender que la misma se despliega en el ámbito de las relaciones políticas entre los cargos electos y los órganos de gobierno. Exigencia que, como hemos comprobado, ha distado mucho de satisfacerse en este supuesto, lo que ha de conducir a la inadmisión de la presente reclamación. Pues, ciertamente, como apuntamos en la Resolución 89/2016 y ahora resulta pertinente reiterar, «so pena de distorsionar el entero sistema institucional, el derecho de acceso a la información pública configurado en la legislación de transparencia no debe ser instrumentalizado a modo de fórmula para prolongar o extender artificialmente las vías de control político del gobierno...» En el caso de los ERES, se inadmite también y se apoya la inadmisión en el propio escrito de reclamación, «en donde se revela explícitamente que la presentación de la solicitud responde a la ineficacia mostrada por las diversas iniciativas que, desde hacía más de un año, había emprendido la solicitante en su condición de Diputada del Parlamento de Andalucía para acceder a la información pretendida, mencionando de forma específica la aprobación, el 10 de marzo de 2016, de una Proposición no de Ley en Comisión que había comprometido al Gobierno a este respecto».

27 Quizás podría aplicarse aquí el adagio «hard cases make bad law». El Auto núm. 184 del Juzgado de lo Contencioso-administrativo núm. 5 de Sevilla, en relación con la Resolución 96/2016, consideró que había habido satisfacción extraprocesal ya que en el expediente la Administración hizo constar la respuesta que finalmente dio a la solicitud de información en sede parlamentaria. El Auto, por tanto, no entra en el fondo de la cuestión que aquí se analiza, aunque parece más bien favorable a estimar la competencia del Consejo, ya que éste había alegado inadmisibilidad o subsidiariamente satisfacción extraprocesal, y fue este último el argumento acogido.

${ }_{28}$ Resolución 18/2017, de 8 de febrero (Ayuntamiento de Frigiliana). Se solicitaba información sobre el fundamento legal para el aumento del número de tenientes de alcalde. 
de nuevo éste se plantea de oficio la admisibilidad. Y, consciente de que diversos Consejos autonómicos están resolviendo en sentido inverso, hace un esfuerzo adicional por añadir argumentos a su favor. Por una parte, se apoya en la auctoritas del CTBG estatal (y manifiesta que su doctrina «es, en lo fundamental, la que igualmente sigue el Consejo estatal de Transparencia y Buen Gobierno»). Por otra, aporta ahora un argumento que no había manejado hasta el momento: la enmienda presentada durante la tramitación en el Congreso de los Diputados del Proyecto de LTBG que fue retirada, y que precisaba que cabía la reclamación en aquellas materias que tienen una regulación específica de acceso ${ }^{29}$. Añade que eso no significa «en modo alguno» que los concejales tengan una menor protección que la generalidad de la ciudadanía en el marco de la legislación reguladora de la transparencia, pues pueden libremente optar entre los dos regímenes vinculando su elección tanto al órgano de gobierno como al propio concejal (obviando que en la resolución anterior, en que la parlamentaria había optado por el régimen de la Ley de Transparencia de forma expresa y a través del cauces procedimental creado ad hoc para ello, el Portal de Transparencia). Eso sí, evitando toda confusión entre ambas vías porque «sencillamente, a nuestro juicio, no se puede pretender seguir uno de tales grupos normativos a unos efectos y abandonarlo a otros efectos». Aplicada esta doctrina al caso, declara la inadmisión puesto que, habida cuenta de los datos en juego, la solicitud se presentó como concejal y conforme a la normativa local ${ }^{30}$.

En definitiva, el Consejo andaluz va un paso más allá que el estatal. No sólo inadmite las reclamaciones cuando las solicitudes se han planteado de conformidad con la normativa que regula el acceso a la información de los representantes políticos, sino que, además, los representantes políticos no son libres de elegir una vía (la de la normativa de transparencia) tras haber intentado antes la otra (la de la normativa parlamentaria o local). El balance, finalmente, es que ningún parlamentario o concejal andaluz, haya actuado en su condición de tal o en la de ciudadano, ha obtenido información adicional a través de reclamaciones ante el CTPDA.

3. La competencia de las Autoridades de transparencia para conocer las reclamaciones presentadas por representantes políticos, también cuando se invoca la normativa especial, por la aplicación supletoria de la normativa general sobre transparencia y acceso a la información y la procedencia del «espigueo» a la hora de aplicar las normas sustantivas o procedimentales de la normativa general si son más favorables al derecho de acceso.

Un criterio bien diferente a los anteriores es el sentado por la Comisión de Garantía del Derecho de Acceso a la Información Pública de Cataluña (GAIP), y adoptado posteriormente por otras Autoridades autonómicas de transparencia.

29 «Que las materias cubiertas por un régimen específico de acceso a la información quedan al margen de estas reclamaciones -por mandato de la Disposición adicional primera LTAIBG-, es la interpretación que asumió con toda evidencia el legislador, tal y como se desprende del análisis de la tramitación parlamentaria de dicha Ley. Así es; precisamente porque los parlamentarios partían de dicha lectura es por lo que aquellos partidarios de abrir las reclamaciones a estas materias consideraron imprescindible que se recogiese expresamente esta posibilidad en el texto de la Ley en formación. En esta línea, la enmienda núm. 476 presentada en el Congreso por el Grupo Parlamentario socialista pretendía la siguiente modificación del art. 21.1 del Proyecto (actual art. 24.1 LTAIBG): "Frente a toda resolución expresa o presunta en materia de acceso, incluidas las que puedan adoptarse en relación con materias que se rijan por normativa específica, podrá interponerse una reclamación ante el Consejo de Transparencia...". La motivación de la enmienda era, por lo demás, obvia a la vista de la interpretación de la Disposición asumida por la generalidad de los parlamentarios: "Extender la posibilidad de reclamación potestativa ante el Consejo Estatal de Transparencia y Acceso a la Información Pública a aquellas materias que tienen una normativa específica de acceso a la información" (BOCG, Congreso de los Diputados. Serie A, núm. 19-3, de 2 de julio de 2013, pág. 250). La enmienda no se incorporaría al Informe de la Ponencia, y el Grupo Parlamentario Socialista no la mantendría para su debate en el Pleno (BOCG, Congreso de los Diputados. Serie A, núm. 19-5, de 9 de septiembre de 2013, pág. 28). Su rechazo no vendría, pues, sino a ratificar y hacer aún más visible que la voluntas legislatoris fue excluir a las materias mencionadas en la repetida Disposición adicional de la reclamación potestativa ante las autoridades independientes de control. Inequívoca voluntad del legislador que este consejo no puede soslayar en sus resoluciones.».

30 «Así se desprende ya con toda evidencia de la circunstancia de que fuera durante una sesión plenaria cuando la ahora reclamante inquiriese por vez primera al alcalde Presidente acerca del artículo del ROF que permitía que se hubiese elevado a cuatro el número de Tenientes de Alcalde de la Corporación. Y la posterior petición, presentada por escrito, de que el secretario interventor elaborase un informe sobre tal cuestión, no se formuló como una solicitud de información en el marco de la LTPA. Por otra parte, tampoco en el escrito de reclamación presentado ante este Consejo se argumenta en torno a una posible inobservancia de la LTPA ni, de hecho, se hace ninguna mención a la legislación en materia de transparencia. Antes al contrario, en dicho escrito se reconoce explícitamente que la pregunta la formuló "como concejal miembro de la corporación actual..."». 
Desde la primera vez que se le planteó, la Autoridad catalana ha venido admitiendo a trámite las reclamaciones de electos locales, a las que, si se identifican como tales y piden información a su respectivo ente local, les aplica las disposiciones de la normativa local, por ser un régimen especial en el sentido de la disposición adicional primera ${ }^{31}$, y supletoriamente la Ley de Transparencia autonómica. Una de las consecuencias de esta supletoriedad es la extensión a estas solicitudes de la posibilidad de interponer la reclamación voluntaria y gratuita, prevista en la normativa de transparencia, lo que «también» se justifica en que sería un contrasentido que los concejales tuvieran menores garantías que el resto de los ciudadanos ${ }^{32}$. Es más, en cuanto al régimen sustantivo y procedimental, precisa que tendrá lugar la aplicación preferente de la normativa específica "especialmente si son más favorables al acceso», como ocurre con la regulación de los límites ${ }^{33}$, aunque «eso no quita que, si se diera el caso, en virtud de la especial relevancia que nuestro ordenamiento jurídico vigente da al derecho de acceso a la información pública, seguramente habría que aplicar las disposiciones de la LTAIPBG, que son posteriores, más favorables al acceso, con preferencia a las de la LMRLC)». De este modo, la condición de representante político juega en sentido favorable a una mayor posibilidad de acceso a la información (por ejemplo, en la interpretación de los límites). Este criterio lo aplica cualquiera que sea la normativa que se haya invocado, de transparencia, local o ninguna, al considerar que no es exigible la invocación de normativa alguna.

Al poco de sentar esta doctrina general, hubo de hacer frente a un cuestionamiento directo de su competencia por parte de la entidad reclamada, una Diputación, lo que le obligó a desarrollar sus argumentos ${ }^{34}$. Admitió sin ambages que la normativa local es una regulación específica a los efectos de la normativa sobre transparencia, caracterizada por el sujeto que la ejerce y su conexión con el derecho fundamental a la participación política, por lo que diseña un régimen reforzado de acceso del que es expresiva la previsión en la normativa local de que los representantes locales tendrán en todo momento acceso libre o directo sin necesidad de solicitud escrita a la información que sea de libre acceso para la ciudadanía, «en lo que se puede considerar una remisión dinámica a la legislación de transparencia vigente en cada momento». Se apoya, además, en las sentencias de 15 de junio de 2015 del Tribunal Supremo, a las que antes hicimos alusión.

${ }^{31}$ En Cataluña, el artículo 164 del Texto refundido de la Ley de Régimen Local de Cataluña, que es más favorable que el estatal, con plazo de resolución de 4 días y derecho incondicionado a copia, entre otros.

32 Esta línea doctrinal la inicia la Resolución de 11 de febrero de 2016, de finalización de la reclamación 4/2016, que sienta la doctrina después reproducida y aplicada en las posteriores resoluciones. El caso era el de la solicitud de información presentada por concejales de un grupo municipal en su condición de tales, a la que su Ayuntamiento no da respuesta. El razonamiento y la conclusión son los siguientes: "Una de las cuestiones no reguladas por la LMRLC, que sólo dedica al derecho a la información de los miembros de las corporaciones locales el precepto citado más arriba y poco más, es la previsión de una vía específica de garantía que pueda proteger el ejercicio de este derecho, de modo que si las solicitudes de información no son atendidas debidamente, el único remedio que tendrían los concejales o concejalas solicitantes sería el recurso contencioso administrativo. A partir de la entrada en vigor de la LTAIPBG esta falta de garantía específica queda cubierta por la regulada en sus artículos 39 a 43 , que son de aplicación supletoria a la legislación de régimen local, por lo que proporcionan a los miembros de las corporaciones locales una vía gratuita y voluntaria, previa eventualmente al contencioso administrativo, para garantizar la efectividad de su derecho a la información. El acceso de los electos locales a esta vía de garantía de su derecho a la información de la respectiva entidad también se justifica en el hecho de que no tendría ningún sentido que los concejales, en el ejercicio de un derecho fundamental como es el del artículo 23 de la Constitución, tuvieran menores garantías para ejercer su derecho específico de acceso que el resto de los ciudadanos, que sí cuentan con la protección adicional y gratuita de la GAIP. En definitiva, la garantía del derecho de acceso proporcionada por la reclamación ante esta Comisión es aplicable en defensa del derecho de los concejales y de las concejalas a obtener información de su propio Ayuntamiento, con la condición de que para la resolución de estas reclamaciones la GAIP debe aplicar preferentemente el derecho a la información regulado por el artículo 164 LMRLC y por las demás disposiciones de la legislación de régimen local que sean de aplicación, especialmente si son más favorables al acceso, y sólo supletoriamente las disposiciones de la LTAIPBG (eso no quita que, si se diera el caso, en virtud de la especial relevancia que nuestro ordenamiento jurídico vigente da al derecho de acceso a la información pública, seguramente habría que aplicar las disposiciones de la LTAIPBG, que son posteriores, más favorables al acceso, con preferencia a las de la LMRLC).».

${ }^{33}$ En esta misma resolución, se apunta ya que los límites al derecho de acceso de los electos locales son los del 164.3 LMRLC (derecho al honor, a la intimidad personal y familiar y a la propia imagen, secretos oficiales o secreto sumarial), «mucho más limitados que los establecidos por los artículos 21 y siguientes de la LTAIPBG. Esta desigual regulación de los límites aplicables al acceso a la información es perfectamente comprensible, ya que se justifica tanto en la lógica mayor intensidad del derecho de acceso cuando es ejercido por miembros de una corporación local, en relación con información de la respectiva administración, como en el hecho de que estos representantes públicos quedan vinculados al deber de respetar la confidencialidad de la información obtenida en ejercicio de este derecho».

34 En la Resolución de 7 de julio de 2016, que trae causa de la reclamación 34/2016, la entidad reclamada discute la competencia de la GAIP. El solicitante es el portavoz de un grupo de una Diputación catalana que pide información sobre el listado de movimientos del anticipo de caja fija de un área de la Diputación y las facturas y justificaciones correspondientes. Presentada reclamación, la Diputación alegó que la GAIP no es competente porque ninguna norma le atribuye funciones de tutela del derecho de los cargos electos, siendo las vías el recurso de reposición y la tutela judicial, por el procedimiento ordinario o por el especial de protección de los derechos fundamentales. 
REALA. Nueva Época - N. 8, noviembre 2017 - ISSN: 1989-8975 - DOI: 10.24965/reala.v0i8.10439 - [Págs. 27-48]

El acceso de los representantes políticos a la información y la nueva normativa sobre transparencia y acceso a la información ...

Emilio Guichot

Por eso mismo, sería incoherente privar a los representantes locales de un mecanismo adicional de garantía de utilización potestativa y que no empece para el uso de los demás ya disponibles antes de la aprobación de la normativa sobre transparencia, sin que la normativa local prohíba su existencia ni sea incompatible con ella. Máxime, cuando se trata de una normativa anterior en el tiempo, por lo que no pudo remitirse a ella. Además, en esta resolución, aplica el límite de la intimidad, previsto en la normativa local catalana, y no el de la protección de datos de la normativa sobre transparencia, si bien lo confronta, en la ponderación, con el interés público en la divulgación al que se refiere la normativa general sobre transparencia y acceso a la información (lo que le lleva a considerar que prevalece el interés de los representantes locales en conocer cómo se gasta el dinero público con tarjetas bancarias en poder de los cargos públicos), prevalencia que se ve fortalecida por el deber de confidencialidad que, conforme a la normativa local, pesa sobre los electos locales respecto de la información a la que tengan acceso por razón de su cargo, y que prohíbe que se haga una difusión indebida de esta información (y que no impide la denuncia de comportamientos ilegales que puedan afectar al uso de las tarjetas, pero sí la utilización de la información obtenida para fines ajenos a las funciones del cargo electo, difundir los gastos realizados cuando se encuentren justificados y se ajusten a la legalidad e incluso difundir datos de actuaciones ilegales que puedan afectar a la intimidad y que no sean de interés público). Sobre el período de tiempo que puede abarcar la solicitud de información y, en concreto, si ha de ceñirse al mandato actual, como alegaba la Diputación, considera que no existe límite alguno, pues para ejercer adecuadamente las funciones es también necesario conocer los antecedentes $y$, al respecto, toma de nuevo en consideración que la normativa general sobre transparencia y acceso a la información no establece limitación temporal alguna, por lo que «si cualquier ciudadano, al amparo de la legislación de transparencia (que no establece ninguna limitación temporal a las informaciones que se pueden pedir), puede solicitar acceso a informaciones de mandatos precedentes, sin necesidad de motivar su solicitud (artículos 18.2 y 26.2 LTAIPBG), con más razón deben poder hacerlo los cargos electos locales. En caso contrario se impediría la exigencia de responsabilidades políticas y jurídicas una vez finalizado el mandato corporativo y se vaciaría de contenido la función de control y fiscalización de los cargos electos de la oposición». Asimismo, interpreta en sentido favorable al acceso, en línea con la normativa general sobre transparencia y acceso a la información, la normativa local en cuanto a la innecesariedad de motivar la solicitud o el derecho a obtener copias.

Resoluciones posteriores han puesto aún más de relieve cómo la condición de representante local, y la importancia del derecho fundamental ex art. 23.2 CE que ejercen, juega un papel a veces decisivo en la ponderación, inclinando la balanza en favor de la transparencia cuando colisiona con otros derechos constitucionales como el derecho a la intimidad (o el acceso a datos «especialmente protegidos» en la nomenclatura de la normativa sobre protección de datos). Así, ha justificado que se dé acceso a datos de infracciones y sanciones prescritas referidas a cargos electos, personal directivo, de confianza y eventual de la Administración municipal y de sus entes instrumentales (que se negarían a un ciudadano común por imperativo de lo dispuesto en el art. 15.1 LTBG) ${ }^{35}$. Y en que la normativa general sobre transparencia no es

\footnotetext{
35 Así en las Resoluciones de 14 de septiembre de 2016, 78, 116, 117 y 118/2016 (acumuladas). El solicitante era un grupo municipal que reclamaba información sobre infracciones y sanciones prescritas referidas a cargos electos, personal directivo, de confianza y eventual de la Administración municipal y de sus entes instrumentales. Apelan a la normativa local catalana. La GAIP reafirma su competencia. Por lo demás, el Ayuntamiento implicado no lo cuestionaba. Considera que entre los límites contemplados en la normativa local sólo podría jugar el relacionado con la intimidad personal. Al respecto, entiende que si quien solicitara la identificación fuera un ciudadano, y no un concejal (en este caso, un grupo municipal), se tendría que denegar el acceso por imperativo del límite contenido en la normativa sobre transparencia ya se trata de un dato especialmente protegido, y el acceso se condiciona en este caso al consentimiento expreso del afectado o una norma con rango de ley lo ampare (pese a que como certeramente afirma el GAIP, «ciertamente, existirían argumentos materiales ligados al control ciudadano de la honorabilidad de los gobernantes que podrían justificar conceder acceso a las infracciones administrativas que hayan podido cometer, al menos mientras ocupen el cargo»). "Sin embargo, la posición de los concejales es distinta de la de la generalidad de la ciudadanía». La normativa local no se apoya en los conceptos de «datos personales» y «datos especialmente protegidos» sino en el de «intimidad». Ciertamente la categoría de «dato íntimo» y "dato especialmente protegido» en gran medida se yuxtaponen pero «no parece ser el caso de determinados datos relativos a la comisión de infracciones y sanciones administrativas», como no lo eran en el artículo 37 Ley 30/1992 y como piensa un amplio sector doctrinal. En todo caso, no quedaría afectada la intimidad si no se da acceso al conocimiento de las concretas infracciones cometidas (que pueden revelar datos de salud, vida sexual...), sino sobre el número de denuncias y sanciones administrativas archivadas en relación con una determinada persona «y menos aún si esta persona tiene la condición de cargo electo, de alto cargo o de personal directivo de la Administración municipal o de sus entes instrumentales. En cambio, existe un interés público evidente en el control del correcto ejercicio de la potestad sancionadora municipal, y el acceso por parte de los concejales de la oposición a la identidad de los cargos públicos municipales a los que se han archivado expedientes sancionadores en un período de tiempo determinado es necesario a fin de que aquellos puedan ejercer debidamente su tarea esencial de control y fiscalización de la actividad del consistorio (artículos 22.2.a LBRL y 52.2 a TRLMRLC)
} 
REALA. Nueva Época - N. 8, noviembre 2017 - ISSN: 1989-8975 - DOI: 10.24965/reala.v0i8.10439 - [Págs. 27-48]

El acceso de los representantes políticos a la información y la nueva normativa sobre transparencia y acceso a la información ...

Emilio Guichot

aplicable a los electos locales en aquello que pueda resultar más restrictivo, pero sí en lo que pueda reforzar su derecho de acceso ${ }^{36}$.

Otros Consejos autonómicos han seguido la vía del catalán.

Así, el Consejo de Transparencia, Acceso a la Información Pública y Buen Gobierno de la Comunidad Valenciana considera que las solicitudes de información de los representantes locales, efectuadas en su calidad de tales, se rigen por la normativa local, básica estatal y supletoria autonómica, pero conforme a la disposición adicional primera de la LTBG, la LTBG y la normativa autonómica de desarrollo son supletorias, supletoriedad que se extiende a la posibilidad de reclamar ante el Consejo, pues la garantía de los concejales en ejercicio de su derecho fundamental, tanto sustantiva como procesal, no puede ser menor que la del resto de los ciudadanos, apelando también a reseñada jurisprudencia del Tribunal Supremo ${ }^{37}$. Y ello más cuando que la reclamación es potestativa y no impide la utilización de las vías de tutela derivadas de la normativa local. La normativa de aplicación sería «preferentemente» la normativa local, «especialmente si son más favorables al acceso, y solo supletoriamente las disposiciones de la Ley de Transparencia» ${ }^{38}$.

Por su parte, el Comisionado de Transparencia de Canarias ha resuelto reclamaciones formuladas por representantes locales que se identificaron como tales en las respectivas solicitudes y que invocaban tanto la normativa local como la de transparencia ${ }^{39}$. Parte de la doctrina del CTBG. Constata que hay una regulación específica, integrada por las bases estatales y la normativa de desarrollo autonómica sobre régimen local, que cuenta con dos vías de protección ordinaria -el recurso de reposición y el contencioso-administrativo- y dos adicionales -el "amparo ordinario» y el constitucional-. De este modo, tras la entrada en vigor de las Leyes estatal y autonómica de transparencia, existen dos vías en virtud de las cuales los cargos representativos locales pueden ejercer el derecho de acceso a la información de su respectiva entidad local

y detecten eventuales negligencia y tratos de favor. Las consecuencias de este acceso se encuentran, además, limitadas por el deber de reserva o confidencialidad impuesto a los concejales por el artículo 164.6 TRLMRLC, y que el propio grupo municipal reclamante se compromete a observar en su escrito de solicitud». Por ello, considera que ha de entregarse la información con una lista nominal de los cargos públicos que contenga tan sólo el cargo, el número total de expedientes sancionadores archivados y el motivo del archivo.

36 Resolución de 28 de septiembre de 2016, 142/2016. Un grupo municipal solicitó información sobre las condiciones laborales de los trabajadores de empresas contratistas, sobre el coste del cumplimiento de un convenio con una asociación privada, sobre el salario de los trabajadores municipales y otras. Reitera su competencia, pese a un informe del secretario municipal sobre la no aplicación supletoria de esta garantía. La GAIP considera que la regulación del derecho de acceso de la Ley de Transparencia no es aplicable a los electos locales en aquello que pueda resultar más restrictivo, pero sí en lo que pueda reforzar su derecho de acceso, de modo que si cualquier ciudadano puede pedir a la Administración datos de sus contratistas directamente relacionados con el contrato suscrito, con más motivo lo tienen que poder hacer los cargos electos locales.

37 Resolución 6/2017, de 9 de febrero. Un concejal solicita información diversa, obteniendo la callada por respuesta. En el mismo sentido, Resolución $7 / 2017$, de 9 de febrero. Un concejal solicita la misma información por escrito y en el Pleno, sin obtener contestación.

38 «Ahora bien, en tanto la regulación de la ley 19/2013, de 9 de diciembre, de Transparencia ofrece y garantiza una mejor tutela del derecho de acceso a la información así como la vía de reclamación ante esta Comisión cosa que no abarca la Ley $6 / 2010$ de Régimen Local, es lógico que el derecho de acceso a la información que se garantiza a cualquier ciudadano no tenga mejores garantías que el derecho reforzado de acceso a la información de los cargos electos en el ejercicio de su función institucional y del derecho fundamental del artículo 23.2 de la Constitución Española, tal y como se manifestó en la resolución del Tribunal Supremo 2870/2015, de 15 de junio al expresar que el acceso a la información y a los documentos públicos no solo no podrán ser inferiores a los que tiene ya a su disposición cualquier ciudadano en virtud de esas leyes sino que deben suponer un plus añadido imprescindible. Por tanto, de acuerdo con este criterio jurisprudencial si la Ley de Transparencia ofrece a la ciudadanía en general una vía de reclamación y garantía gratuita y unos plazos de resolución mucho más breves, los cargos electos no pueden estar en peores condiciones para obtener la tutela de su derecho de acceso, reforzado por una norma específica de la que, por expresa previsión de la Disposición adicional primera de la Ley de Transparencia, ésta es supletoria. Así, teniendo en cuenta que la reclamación ante esta comisión es potestativa y opcional, la aplicación de la Ley de Transparencia ante esta comisión no se impone ni sustituye los otros mecanismos que pueden ser utilizados igualmente por los cargos electos si lo consideran adecuado, tal y como ha solicitado XXX. Por ello, la garantía del derecho de acceso proporcionada por la reclamación ante esta Comisión es aplicable en defensa del electo local a obtener información de su propia entidad siempre que para la resolución de estas reclamaciones se aplique preferentemente el derecho a la información regulada por el artículo 128 de la Ley 6/2010, de 23 de junio, de la Generalitat, de Régimen Local de la Comunitat Valenciana y por las demás disposiciones de la legislación local que sean aplicables, especialmente si son más favorables al acceso, y solo supletoriamente las disposiciones de la Ley de Transparencia.».

39 Resoluciones 61/2016, de 31 de marzo, 62, 63 y 64/2016, de 1 de abril, 65 y 66/2016, de 2 de abril, 67/2016, de 4 de abril, 68/2016, de 5 de abril, 69/2016, de 6 de abril, 75/2016, de 12 de abril, 76/2016, de 13 de abril, 77/2016, de 14 de abril, 78/2016, de 15 de abril, 85/2016, de 22 de abril, 86/2016, de 23 de abril. En todos los casos, las reclamaciones habían sido interpuestas por consejeros de un mismo Cabildo salvo en el caso de la 78/2016, en que la había interpuesto el Grupo Mixto (suscrita por sus cuatro consejeros). Se había apelado en las solicitudes a la normativa local y a la de transparencia y en las reclamaciones sólo a la de transparencia. En todas ellas, el Cabildo había dado la callada por respuesta y ya una vez interpuestas reclamaciones en sus alegaciones exponía que la normativa de aplicación era la local y que se trataba de solicitudes abusivas y masivas, para cuya atención no disponía de medios humanos. 
para el ejercicio de su función. La específica prevista en la normativa local, que «debería ser la vía habitual y ordinaria para el ejercicio de acceso», si bien añade que "el día a día de este ejercicio se ha mostrado en muchas ocasiones como problemático, con numerosas reclamaciones ante los tribunales de justicia y quejas ante los órganos encargados de defender los derechos fundamentales y las libertades públicas». La segunda vía es la de la normativa de acceso a la información, desde el momento en que la titularidad se atribuya a todas las personas, que pueden también utilizar los representantes locales, «como ciudadanos cualificados por su motivación de ejercicio de cargo público». Hasta aquí el propio Comisionado canario estima que «el criterio expuesto, es coincidente con la consulta CO 105/2015 del Consejo de Transparencia y Buen Gobierno estatal» (si bien ya ha manifestado, nótese, que la protección por la vía especial es problemática y que cuando se actúa por la vía general se actúa como ciudadano cualificado). A continuación analiza el sentido de la referencia a la supletoriedad del párrafo segundo de la disposición adicional primera de la LTAIP, similar a nuestros efectos al correspondiente de la LTBG. Constata que la normativa local estatal, anterior en el tiempo a las Leyes de transparencia, sólo prevé los recursos ordinarios (reposición y contencioso), y que la canaria, posterior a ellas, no comprende ningún régimen específico de garantía, a diferencia de lo que hacen las leyes de transparencia, estableciendo «una vía que mejora y completa un régimen de garantía del derecho de acceso a la información de los cargos públicos, que además es gratuita, rápida y resuelta por un órgano independiente, a diferencia del sistema alternativo, en el que resuelve la propia corporación afectada por la reclamación». De tal forma que sería contradictorio y contrario a la jurisprudencia del Tribunal Supremo que un derecho reforzado como es el de los representantes locales careciera de una garantía accesible a la generalidad de los ciudadanos ${ }^{40}$. De hecho, la afirmación tiene un carácter general que excede a la posibilidad de plantear una reclamación, para extenderse a cualquier mejora (sustantiva, procedimental) de la regulación en la normativa general sobre transparencia y acceso a la información respecto a lo dispuesto en la normativa sectorial o específica ${ }^{41}$. Y, al igual que la Autoridad catalana, defiende que la condición de representante local ha de tomarse en consideración en la ponderación a los efectos de añadir peso en el platillo de la balanza de la transparencia ${ }^{42}$. Aun más, considera que la normativa de aplicación preferente para resolver las reclamaciones es la de transparencia, sin que quede condicionada la aplicación de este bloque normativo a que se haya invocado en la solicitud ${ }^{43}$.

El Consejo de Transparencia de Aragón se ha pronunciado recientemente en el mismo sentido. Constata que la doctrina del CTBG y de los Consejos autonómicos que se han pronunciado sobre la cuestión

40 «El derecho de acceso de los consejeros insulares y concejales es un derecho constitucionalmente reforzado y privilegiado en comparación con el que ostentan los ciudadanos particulares. Representaría un claro contrasentido que no pudiera beneficiarse de las mismas garantías que se reservan al acceso ciudadano. Por ello, se ha de entender que será de aplicación supletoria la normativa de la LTAIP en la medida que refuerce el acceso a la información de los cargos electos locales en el ejercicio de sus funciones, en contraste con las previsiones que supongan un tratamiento más restrictivo. Y ello por la evidente razón de que el derecho de los ciudadanos no puede ser de mejor condición que el de los representantes políticos de las administraciones locales, de cabildos y ayuntamientos. El propio Tribunal Supremo ha validado esta mayor protección al derecho de acceso de los cargos representativos locales en la STS de 15 de junio de 2015 (RJ 2015, 4815), que, aunque referida a los representantes autonómicos, es plenamente aplicable a este caso. En dicha sentencia, se indica que "tras la Ley 10/2013, de 9 de diciembre, de transparencia, acceso a la información y buen gobierno [...] el derecho de acceso de los parlamentarios a la información pública no puede verse sino fortalecido. En efecto, a fin de que estén en condiciones adecuadas para hacer frente a la especial responsabilidad que les han conferido al elegirlos, habrán de contar con los medios necesarios para ello, los cuales en punto al acceso a la información y a los documentos públicos no sólo no podrán ser inferiores a los que tiene ya a su disposición cualquier ciudadano en virtud de esas leyes, sino que deben suponer el plus añadido imprescindible".».

${ }_{41}$ «Por tanto, el derecho de acceso a la información de los cargos representativos locales es un régimen especial de acceso a la información reforzado, al que le es de aplicación supletoria las mejoras en el régimen de acceso a la información pública que se derivan dela LTAIP, que ha derogado implícitamente las regulaciones previstas en otras normas, como sucede, con aquellas previsiones del Reglamento de Organización, Funcionamiento y Régimen Jurídico de las Entidades Locales que se opongan o contradigan a la reiterada a la LTAIP y a la Ley 19/2013, de transparencia, acceso a la información pública y buen gobierno, como es el caso de la vía de reclamación ante este Comisionado de Transparencia y Acceso a la Información Pública.».

${ }^{42}$ En efecto, se plantea a continuación cuál es la legislación aplicable por la autoridad de transparencia al conocer las reclamaciones, en relación con la disposición de la Ley canaria que relaciona las reclamaciones con las resoluciones de las solicitudes de acceso «que se dicten en el ámbito de aplicación de esta ley» (dicción que difiere del art. 24.1 LTBG que se refiere a «toda resolución expresa o presunta en materia de acceso», sin apelar a ley concreta alguna). Considera que «este marco de la LTAIP, unido al principio de competencia en la actuación pública, nos delimita una aplicación preferente por el Comisionado de Transparencia y Acceso a la Información Pública a la LTAIP, considerando al consejero o concejal que reclama como un ciudadano cualificado a la hora de aplicar la proporcionalidad y justificación en la posible ponderación de los límites al derecho de acceso (artículo 37 LTAIP) y en la ponderación del interés público y los derechos de los afectados en materia de protección de datos personales (artículo 38 LTAIP)».

${ }^{43}$ Aplicando los principios de eficacia y antiformalista, afirma que: «no obstante, se considera que el derecho de acceso a la información pública pertenece al ciudadano consejero o concejal y no puede quedar condicionado por la cuestión formal del bloque normativo alegado en su solicitud». 
contienen «planteamientos y posiciones no siempre coincidentes», comprueba que finalmente la doctrina del CTBG y de los Consejos andaluz y castellano-leonés conducen a que el representante local plantee la reclamación por la vía de la normativa de transparencia si antes lo hizo sin éxito por la vía local, para poder así acudir a la reclamación, y concluye que «por razones de carácter pragmático, la competencia para conocer de una reclamación no puede quedar condicionada por la cuestión formal del bloque normativo alegado en la solicitud, pues ello, contrariamente a lo que se afirma en las últimas resoluciones del CTBG y del Consejo de Transparencia y Protección de Datos de Andalucía, sí que afecta al principio de seguridad jurídica» y admite la reclamación. En cuanto al fondo, un concejal solicitaba copia de los expedientes de dos contratos menores. Se le dio acceso in situ pero se denegó la copia, «por no tener derecho a la copia indiscriminada de cualquier expediente administrativo». El Consejo aragonés considera que es discutible la vigencia de la limitación al derecho a obtener copia del art. 16.1.a) ROF a la vista de la vigente normativa de transparencia, ya que «es inconsecuente que los ciudadanos tengan el derecho a solicitar el envío de copias, de forma gratuita si son en formato electrónico [...], y se niegue el derecho a los representantes locales, por lo que la previsión del ROF en este punto debe entenderse superada, siempre que el derecho no se ejerza de forma abusiva en los términos que se han señalado, límite, por otra parte, también válido para los ciudadanos» ${ }^{44}$.

Otras Autoridades autonómicas aún no han fijado una doctrina clara, si bien los pronunciamientos parecen favorables a admitir las reclamaciones ${ }^{45}$.

\section{VALORACIÓN Y CONCLUSIONES}

\section{La competencia de las Autoridades de transparencia para conocer de las reclamaciones interpuestas por representantes políticos en su condición de tales}

A nuestro juicio, ha de operarse con una interpretación gramatical, histórica, sistemática y teleológica de la normativa, general y especial, sobre acceso a la información.

- Gramaticalmente, la disposición adicional primera se refiere en su apartado segundo a la aplicación "con carácter supletorio» de la LTBG a las materias que tengan previsto un régimen jurídico específico de acceso a la información y muestra cuál es su entendimiento del término en su apartado tercero, que, a modo de especificación («en este sentido»), hace equivaler supletoriedad con aplicación de la Ley «en lo no previsto en sus respectivas normas reguladoras». Además, muestra un entendimiento lato del término «materia» (la información destinada a la reutilización no se refiere, como la ambiental, a un sector de la realidad, sino a una finalidad). Ello nos permite, aplicado a nuestro objeto de estudio, colegir que la regulación (sustantiva, material, de garantías) de la LTBG se aplicará al acceso por los representantes políticos a la información, que cuenta con una regulación específica, aunque en este caso no en atención a la materia, pero sí a la finalidad, cual es la de posibilitar el ejercicio del derecho fundamental del art. 23.2 CE, en lo no previsto, y lo cierto es que la normativa local no prevé ningún sistema específico de recursos en materia de acceso a la información, ni administrativos ni judiciales. Si acudimos a la regulación de la reclamación del art.

44 Resolución 6/2017, de 27 de marzo.

45 Así, en el caso de la Comisión de Transparencia de Galicia («integrada» en/por el Valedor do Pobo), la Resolución 25/2016, de 15 de diciembre de 2016, de la Comisión de Transparencia de Galicia se refiere a una solicitud por un concejal de acceso a libros de actas del Municipio anteriores a la Guerra Civil en que se invocaba el ROF. En la reclamación, invocó, además, la Ley 30/1992 y la Ley autonómica de transparencia. La Comisión considera normativa aplicable las Leyes estatal y autonómica de transparencia, y tiene en cuenta la legislación local, pero descarta que sea de aplicación porque habría precisado de justificación de que la información es precisa para el ejercicio de las funciones de concejal y además habría debido entenderse que había sido concedida por silencio positivo. La Comisión alude al artículo correspondiente de la Ley autonómica que le otorga la competencia para conocer de las reclamaciones. Ahora bien, advierte de que el acceso a esa información se rige por la normativa específica de archivos autonómica. Y, sin más razonamiento, obliga a tomar las medidas necesarias para asegurar el acceso. Por su parte, en la Resolución 50/2016, de 8 de marzo, de la Comisión de Transparencia de Galicia, una concejala pide copia de las actas de la Junta de Gobierno local, apelando a la normativa local y a la imposibilidad de ejercer su labor del control y fiscalización. El Consejo apela a la DA1 pero en lo referente a los procedimientos en curso en los que se tiene la condición de interesado. Establece las diferencias entre el bloque del art. 23.2 CE y la normativa local, de una parte, y el art. 105.b) CE y la normativa sobre transparencia, pero también alude al derecho de los interesados en el procedimiento acogido en la Ley 39/2015. Añade que la normativa gallega de transparencia dice que la información obtenida puede ser posteriormente utilizada sin autorización y que no exige la condición de interesado, mientras que la información obtenida por los concejales está sometida a deberes de cautela y de protección de la información. Considera, en fin, que es de aplicación la Disposición adicional primera en la medida en que existe un procedimiento en curso. 
24.1 LTBG, ésta se prevé «frente a toda resolución expresa o presunta en materia de acceso», sin distinguir entre materias generales y materias objeto de regulación específica, con lo cual la literalidad no supone obstáculo alguno a la competencia ${ }^{46}$.

- Históricamente, la regulación del acceso de los representantes políticos a la información es anterior a la aprobación de la LTBG, y, por ende, a la previsión de la creación de Autoridades independientes de transparencia (y anterior también a la propia previsión en nuestro Derecho de Autoridades independientes de protección de derechos constitucionales; baste recordar que la Agencia española de Protección de Datos se creó en 1993, con posterioridad a la aprobación de la LBRL, del ROF y de la Ley 30/1992, cuyo artículo 37 reguló por vez primera el derecho de acceso de los ciudadanos a la información). Resulta, por ello, obvio que la normativa local no pudiera referirse a una garantía hasta entonces inexistente.

- Sistemáticamente, resultaría de una incoherencia insoslayable que la normativa especial que desarrolla un derecho fundamental de los representantes políticos que resulta esencial para el ejercicio de sus funcionales, en que se basa el sistema de democracia representativa, se interpretara como que desprovee a éstos de una garantía con la que cuenta el común de los ciudadanos, cual es la de obtener una respuesta gratuita y rápida, por una Autoridad independiente, que posibilita la participación y la rendición de cuentas que se lleva a cabo por los representantes, como mecanismo general de democracia representativa, y por los propios ciudadanos, como mecanismo de democracia directa. La apelación como alternativa al mecanismo «privilegiado» de los representantes, que pueden acudir a un procedimiento judicial especial y sumario, quedan desmentidas, en su efectividad, a la vista de su realidad, que contrasta con la necesidad de inmediatez del acceso a la información para cumplir con su finalidad de participación, control y rendición de cuentas (sin entrar ahora en la jurisprudencia del Tribunal Europeo de Derechos Humanos que reconoce el derecho de acceso a la información pública como integrante de la libertad de expresión e información, de la que antes que tarde tendrá que hacerse eco el Tribunal Constitucional y la jurisdicción ordinaria, sin que parezca que nadie vaya a cuestionarse, si llega ese momento, si al contar con

46 Ciertamente, la seguridad jurídica ganaría si una cuestión como que nos planteamos en este trabajo hubiera incluido una referencia expresa en este sentido. Pudo haber ocurrido de haber prosperado alguna de las enmiendas que en este sentido se plantearon en la tramitación parlamentaria. En efecto, una enmienda planteada por el Grupo socialista en el Congreso precisaba que la reclamación cabía frente a cualquier resolución «incluidas las que puedan adoptarse en relación con materias que se rijan por normativa específica», enmienda que no se mantuvo para el debate en el Pleno. Se trataba de la enmienda núm. 476 presentada en el Congreso por el Grupo Parlamentario socialista, que pretendía la siguiente modificación del art. 21.1 del Proyecto (actual artículo 24.1 LTBG): «Frente a toda resolución expresa o presunta en materia de acceso, incluidas las que puedan adoptarse en relación con materias que se rijan por normativa específica, podrá interponerse una reclamación ante el Consejo de Transparencia...». La motivación de la enmienda era: «Extender la posibilidad de reclamación potestativa ante el Consejo Estatal de Transparencia y Acceso a la Información Pública a aquellas materias que tienen una normativa específica de acceso a la información» (BOCG, Congreso de los Diputados. Serie A, núm. 19-3, de 2 de julio de 2013, pág. 250). La enmienda no se incorporaría al Informe de la Ponencia, y el Grupo Parlamentario Socialista no la mantendría para su debate en el Pleno (BOCG, Congreso de los Diputados. Serie A, núm. 19-5, de 9 de septiembre de 2013, pág. 28). Ahora bien hacer equivaler el no mantenimiento al rechazo y extraer de ello, como hace, según vimos, el Consejo andaluz, la conclusión de que ello supone «ratificar y hacer aún más visible que la voluntas legislatoris fue excluir a las materias mencionadas en la repetida Disposición adicional de la reclamación potestativa ante las autoridades independientes de control» y ver en ello una «inequívoca voluntad del legislador que este consejo no puede soslayar en sus resoluciones» resulta ya un tanto arriesgado. En efecto, también puede interpretarse la no acogida en el Informe de la Ponencia y la posterior retirada como resultantes de la innecesariedad de tal precisión, o de la inconveniencia de extenderla a cualquier materia con regulación específica, tenga o no previsto un sistema específico de recursos (como ocurre, por ejemplo, en el ámbito de la legislación hipotecaria). Más si se tiene en cuenta que la precisión acerca de la posibilidad de presentar reclamaciones en las materias que se rigen por su normativa específica tampoco se encontraba en la proposición de Ley del propio Grupo parlamentario socialista presentada en la misma legislatura [Proposición de Ley de transparencia y acceso a la información pública, 122/000010, presentada por el Grupo parlamentario socialista (BOCG, Congreso de los Diputados. Serie B, núm. 10-1, de 27 de diciembre de 2011, pág. 8, art. 17.1], con lo que, podría también razonarse, que la voluntad del Grupo socialista había sido siempre la misma, la de extender las reclamaciones también a esos casos, y ahora sólo se pretendía su constancia expresa. Una interpretación histórica oficiosa del texto de la Ley que puedo aportar, aunque sea como «confesión» de primera mano, es la siguiente. La disposición adicional primera de la LTBG reproduce literalmente (como lo hace buena parte del articulado) su antecedente en el Anteproyecto de Ley de Transparencia del anterior Gobierno socialista y en su concepción la finalidad principal fue precisamente el juego supletorio de la garantía de la reclamación. En todo caso, la interpretación posterior demuestra que cuanto mayor precisión se lleve a cabo en un texto legal, en estas materias, menos equívocos se producen. De hecho, ni siquiera ha sido obstáculo para el Comisionado canario que la Ley canaria de transparencia que dispone que las reclamaciones se pueden interponer contra las resoluciones de las solicitudes de acceso «que se dicten en el ámbito de aplicación de esta ley» (dicción que difiere del art. 24.1 LTBG que se refiere a «toda resolución expresa o presunta en materia de acceso», sin apelar a ley concreta alguna), que declara la aplicación preferente por el Comisionado de la Ley de transparencia sobre la normativa local en el caso de las reclamaciones interpuestas por representantes locales. 
esa garantía dejaría de tener sentido la garantía adicional de la reclamación ante la Autoridad independiente de transparencia) ${ }^{47}$. Si se quiere una constatación empírica, basta observar la propia experiencia de nuestros representantes políticos, que se han apresurado a acudir a esta nueva vía ante la inefectividad de los mecanismos generales administrativos y judiciales, como hemos podido ver a lo largo de este trabajo. Y, en todo caso, y como ha puesto de relieve la Autoridad catalana y las que le siguen, no supone impedimento jurídico alguno a la disposición de una vía adicional (y ella sí, efectiva) como es la reclamación. El Tribunal Supremo, como vimos, ha aportado, en este sentido, una argumentación que por su claridad y su influencia resulta difícil de superar, y que ha sido manejada, en las resoluciones favorables a admitir las reclamaciones por algunas Autoridades de transparencia y en la doctrina.

- Teleológicamente, el mecanismo de la reclamación ante una Autoridad administrativa independiente está encaminado, precisamente, hacer frente a la inefectividad de la vía de recursos administrativos y contencioso-administrativos para satisfacer un derecho al servicio de la participación, el control y la rendición de cuentas, dado que práctica del derecho de acceso previa a la aprobación de la LTBG, bajo el imperio del art. 37 Ley 30/1992, reveló que en un sistema como aquel, de silencio positivo y recursos administrativos y contencioso-administrativos, llevó a un panorama generalizado de silencios administrativos seguidos de falta de entrega de información y de apenas conflictividad judicial, ante la inutilidad y el coste de emprender esa vía para obtener una información inútil en caso de obtenerse al cabo de años. Por ello, se estableció, en sintonía con la opción abrumadoramente mayoritaria en el Derecho comparado, la garantía de la existencia de Autoridades dotadas de independencia, inspirada en la independencia judicial, y a la vez, con gratuidad y plazos de resolución breves, característicos de los recursos administrativos, apoyándose el legislador para ello en el artículo 149.1.1. ${ }^{\text {a }}$ CE (misma base competencial utilizada para establecer las Agencias de protección de datos en la Ley orgánica 15/1999, de protección de datos de carácter personal, en defensa en ese caso de ese derecho constitucional). Pues bien, en el caso de la regulación especial del derecho de acceso a la información de los representantes locales el panorama es similar al que existía bajo la vigencia de la Ley 30/1992: silencio positivo, recursos administrativos frente a denegaciones ante la misma Administración que dictó la resolución recurso contencioso-administrativo, ante una jurisdicción incapaz de dar una respuesta ágil en breve plazo, cualquiera que sea la vía, ordinaria o preferente utilizada. Por ello, resulta evidente que, creada la vía de la reclamación como novedad institucional para poner remedio a una efectiva falta de garantías, ésta deba extenderse (en sus términos, esto es, como facultativa) también a los representantes políticos que llevan a cabo, por así decirlo, la tarea ordinaria de participación, control y rendición de cuentas en una democracia fundamente representativa.

El resultado práctico, en fin, de la doctrina del Consejo estatal es que conduce a ocultar la condición de los representantes políticos y la invocación de la normativa especial en las solicitudes que formulan, a riesgo de ver inadmitidas sus posteriores reclamaciones. Y ello pese a que en todos los casos analizados, las plantean para obtener información en conexión directa con el ejercicio de su función de control político. En estos casos, gozan de libertad de elección del régimen jurídico aplicable, una elección que no obstante, en el supuesto de que no precisen que solicitan la información conforme a la normativa general (y no a la específica) les conduce a la negación de la garantía. En el caso del Consejo andaluz, además, no les basta con "ocultar» su identidad, sino que además han de tratar de evitar que, por la motivación o por sus alegaciones, o, incluso, de oficio, la Autoridad de transparencia llegue a saber que la solicitud que plantean conecta con su labor de control político (en particular, porque la hayan intentado obtener por la vía de la regulación especial sin éxito, normalmente habiendo obtenido la callada por respuesta). En fin, ver a nuestros representantes políticos ocultando su identidad, o encargando a cualquier otro ciudadano que solicite en su nombre la información para así asegurarse que la Autoridad de tutela del derecho de acceso resolverá su reclamación produce un cierto sonrojo democrático, o sonrojo tout court.

En todo caso, a la vista de la disparidad de criterios en una materia en la que debe primar la máxima seguridad jurídica cual es la de las vías de garantías de los derechos, y a la espera de que próximos pronunciamientos judiciales en procesos ya en curso vayan despejando el panorama, no cabe sino desear que una

47 Sobre el particular, me remito a mi trabajo "Transparencia: aspectos generales", en GUICHOT, E. (coord.), Transparencia, acceso a la información pública y buen gobierno, Tecnos, Madrid, 2014, págs. 35-62, en págs. 36-47. 
REALA. Nueva Época - N. 8, noviembre 2017 - ISSN: 1989-8975 - DOI: 10.24965/reala.v0i8.10439 - [Págs. 27-48]

El acceso de los representantes políticos a la información y la nueva normativa sobre transparencia y acceso a la información ...

Emilio Guichot

futura modificación de la normativa general sobre transparencia y, en su caso, sobre acceso de representantes políticos a la información, aclare este extremo ${ }^{48}$.

\section{La aplicación a los representantes políticos de su normativa específica sólo en lo que sea más favorable al derecho de acceso que la normativa general. Acerca del del «espigueo»}

Junto a la aplicación supletoria a los representantes políticos de la garantía de la reclamación de la que me acabo de ocupar, y que me parece que no ofrece mucha duda jurídica (otra cosa es que por criterio de «política institucional» o incluso de carga de trabajo no se quiera asumir por algunas Autoridades de control) se plantea, como hemos visto, una cuestión de más alcance, cual es la de si la nueva normativa sobre transparencia ha de jugar también algún papel en la interpretación de la normativa especial, en aspectos sí regulados en ella, pero que lo estén de forma más restrictiva que en la normativa general. $\mathrm{O}$, por decirlo en los gráficos términos del debate entre Autoridades de control, si cabe o no recurrir a la técnica del «espigueo» (término acuñado por el CTBG, por clara referencia a la doctrina opuesta de la Comisión catalana elaborada meses antes del uso de esta expresión por el Consejo estatal $)^{49}$. Esto es, si la normativa sobre acceso de los representantes políticos a la información debe ser objeto de una lectura interpretativa que, cuando menos, iguale el nivel de garantía del derecho (en lo sustantivo y en lo procedimental) al del resto de los ciudadanos.

Hay que convenir que estamos aquí ante criterio que no deriva de un entendimiento clásico de la supletoriedad, cuya función propia es la de cubrir lagunas, no a convertirse en un instrumento de igualación de mínimos entre normativa general y normativa especial. Más bien se relaciona con la extensión del carácter básico de la regulación general a la sectorial. Como vimos al comienzo de este trabajo, ¿cómo justificar que la normativa que regula el acceso de los representantes locales a la información pueda obligar a motivar la solicitud o limitar el acceso a copias, por destacar sólo dos puntos? El Tribunal Supremo ya fue «reinterpretando» estas exigencias de la forma más favorable al ejercicio del derecho fundamental de los representantes políticos. Por mi parte, ya me pronuncié al respecto en 2014, tras la aprobación de la Ley estatal, apuntando el principio de que, en ningún caso, los representantes de los ciudadanos, democráticamente elegidos, podían entenderse situados en una peor condición que los propios ciudadanos, regla que debía proyectarse sobre cualquier interpretación de las normativa especial. Posteriormente, en esta misma línea, el Tribunal Supremo se ha convertido «inspirador» del «espigueo», al establecer que "a fin de que estén en condiciones adecuadas para hacer frente a la especial responsabilidad que se les ha confiado al elegirlos, habrán de contar con los medios necesarios para ello, los cuales en punto al acceso a la información y a los documentos públicos no sólo no podrán ser inferiores a los que tiene ya a su disposición cualquier ciudadano en virtud de esas leyes, sino que deben suponer el plus añadido imprescindible».

De nuevo cabe decir que la LTBG perdió una oportunidad para haberlo dispuesto expresamente, abriendo así otro frente de disparidad de interpretaciones entre las Autoridades de transparencia, de modo que sería muy positivo para la seguridad jurídica, en tanto se mantenga esta disparidad, que la jurisprudencia del Tribunal Supremo inspirara una previsión legal expresa en este sentido. O bien un cambio en la normativa especial que reconociera condiciones sustantivas, procedimentales y de garantía adaptadas a la representación política y más favorables al derecho de acceso, o al menos tan favorables como las que disponen el resto de los ciudadanos. En fin, un «espigueo» del régimen legal, en otro de los sentidos del término, esto es, un crecimiento notable.

48 Hay que reseñar, en este sentido, lo previsto en el Reglamento del Parlamento de Cataluña, tras su reforma de 2015. Sus artículos 6 a 11 regulan el acceso de los parlamentarios a la información, de una forma muy favorable al mismo, tanto en lo sustantivo como en lo procedimental, más allá de la normativa general. En su artículo 8.6 dispone lo siguiente: «Los diputados pueden hacer valer su derecho de acceso a la información mediante los mecanismos de garantía establecidos con carácter general por la legislación de transparencia, acceso a la información pública y buen gobierno. La utilización de esta vía es compatible con la aplicación de las demás medidas establecidas por el presente reglamento y no excluye dicha aplicación.». Esta garantía se une a la aplicación de las sanciones a las autoridades responsables de no facilitar la información, también previstas en la normativa general catalana sobre transparencia, que se adicionan a los mecanismos parlamentarios (inclusión si lo pide el diputado afectado, en la primera sesión plenaria que se convoque de una pregunta sobre los motivos que han impedido el acceso y si a criterio del diputado o de su grupo parlamentario la respuesta no está suficientemente fundamentada, puede presentarse una propuesta de resolución ante la comisión correspondiente, que debe incluirse en el orden del día de la primera sesión que se convoque).

${ }^{49}$ EI DRAE define espigueo como «acción y efecto de rebuscar en libros datos para algún trabajo» o, en la siega, "acción de espigar» y «tiempo o sazón de espigar», y espigar como «tomar de uno o más escritos, rebuscando acá y allá, datos que a alguien le interesan» o «coger las espigas que han quedado en el rastrojo» o, «dicho de una persona: crecer notablemente». 
A falta de precisiones legales, de una jurisprudencia definida y en este panorama de resoluciones dispares, no cabe concluir sino reseñando que por el momento, la doctrina que se ha posicionado por el momento sobre el tema lo ha hecho en este mismo sentido de forma unánime: a favor de la extensión de la competencia de las Autoridades de transparencia ${ }^{50} \mathrm{y}$, más en general, a la aplicación de la normativa de transparencia en lo que sea más favorable al derecho de acceso que la regulación del ejercicio del derecho de acceso por los representantes electos ${ }^{51}$.

50 Para I. MARTíN DELGADO, "La reclamación ante el Consejo de Transparencia y Buen Gobierno: un instrumento necesario, útil y ¿eficaz?", XI Congreso anual de la Asociación Española de Profesores de Derecho Administrativo, Febrero 2016, Zaragoza; disponible en la web: http://www.ctcyl.es/archivos/documentos/1_1461669900.pdf; fecha de consulta: 8 de febrero de 2016, pág. 47, «cabe sostener la competencia del Consejo de Transparencia para conocer de reclamaciones relativas a solicitudes a las que sean de aplicación los regímenes especiales de acceso». Para M. A. BLANES CLIMENT (https://miguelangelblanes.com/2017/02/08/los-concejales-pueden-presentar-la-reclamacion-prevista-en-las-leyes-de-transparencia/) ha de reconocerse que los electos locales pueden plantear reclamación, con independencia de si la solicitud de información se ha apoyado en la legislación de régimen local o en la de transparencia, ya que el derecho fundamental de acceso a la información pública pertenece al concejal y no puede quedar condicionado por la cuestión formal del bloque normativo alegado en su solicitud, lo cual afecta gravemente al principio de seguridad jurídica, por la incoherencia que supone, y al principio de igualdad, a la vista de que la interpretación de las Autoridades de transparencia difiere en este punto.

51 GIFREU FONT, J., "La configuración del derecho de acceso a la información pública de los electos locales en el marco de la normativa sobre transparencia", Revista Española de Derecho Administrativo, núm. 181, 2016, págs. 147-189: "Esta Ley puede contribuir a reformular algunas de las cuestiones espinosas que plantea el ejercicio del derecho de información de los cargos electos pues, como quiera que el derecho de acceso de los concejales es un derecho privilegiado en comparación con el que ostentan los particulares, sería un contrasentido que no pudiera beneficiarse de las mismas garantías que se reservan al acceso ciudadano. Así las cosas, puede afirmarse que la regulación contenida en la LTBG les será de aplicación en la medida que contribuya a reforzar el acceso a la información de los cargos electos locales en el ejercicio de sus funciones, en contraste con las previsiones que supongan un tratamiento más restrictivo. Y ello por la evidente razón de que el derecho de los ciudadanos no puede ser de mejor condición que el de los representantes políticos de la Administración local.». Y pone como ejemplos de regulación más progresiva en el ámbito local el que la normativa local no establece causas de inadmisión, ni requiere la apertura de un trámite de audiencia cuando la solicitud afecta a terceros. En cambio, no contiene un régimen peculiar de defensa ante las vulneraciones del derecho de información de los representantes locales. «Pues bien, siendo el de los concejales un derecho reforzado en comparación con el reconocido a los ciudadanos, nada obsta, muy al contrario, para que puedan beneficiarse de este específico sistema de impugnación, ágil y gratuito.». 